\title{
Implicancias ecológicas de la priorización económica en el paisaje cultural. Determinante de orden y sustentabilidad
}

\section{Ecologicals implications of the economic priorization on the cultural landscape. Determinant of order and sustainability}

Diego Subercaseaux-Ugarte*

\begin{abstract}
A systemic and transdisciplinary approach is fundamental to address the current ecological-territorial situation. The cultural landscape corresponds to an object of study epistemologically adequate for the problem of sustainability. The economic rationality considers the maximization of economic profits in the design of the cultural landscape. Sixteen principles pertaining to determinants of economic order have been defined, identifying their effects on the structure of the landscape and establishing and analyzing the main ecological consequences of their occurrence and predominance. These are: decrease of ecological connectivity and diversity of the cultural landscape, diminishing its potential of resilience and restoration, producing extrication between autopoiesis and adaptation, and through this a decrease of ecological adaptability. Ultimately, this generates the unsustainability of ecological services, which are vital for our society.
\end{abstract}

Keywords: sustainability, cultural landscape, determinant of economic order, landscape ecology, landscape structure.

\section{Resumen}

La aproximación sistémica y la transdisciplinariedad son fundamentales para tratar la situación ecológica-territorial actual. El paisaje cultural corresponde a un objeto de estudio epistemológicamente adecuado ante la problemática de la sustentabilidad. La racionalidad económica prioriza la maximización del lucro económico frente al diseño del paisaje cultural (dimensión económica). Se definen 16 principios propios del determinante de orden económico, donde se identifican sus efectos en la estructura del paisaje y las consecuencias ecológicas. Sucede una disminución de la conectividad y de la diversidad ecológica del paisaje cultural, de su potencial de resiliencia y restauración, un desacoplamiento entre la autopoiesis y la adaptación, y así una disminución de su adaptabilidad ecológica. Esto finalmente genera una insustentabilidad de los servicios ecológicos vitales para nuestra sociedad.

Palabras clave: sustentabilidad, paisaje cultural, determinante de orden económico, ecología del paisaje, estructura del paisaje.

* Pontificia Universidad Católica de Chile. Correo-e: dsuberca@uc.cl. 


\section{Introducción}

Un rasgo dominante en la evolución de la sociedad industrial y posindustrial ha sido la creciente industrialización y tecnologización. Las transformaciones técnicas asociadas a aquello están vinculadas y derivan de rasgos y tendencias culturales. Simultáneamente a la consolidación de la sociedad industrial y posindustrial, y sus rasgos y tendencias culturales propias, se ha evidenciado una importante degradación ecológica y el consiguiente agotamiento y deterioro de los recursos naturales. Vivimos un momento histórico crítico en el cual la biodiversidad está disminuyendo drásticamente y numerosos ecosistemas se están degradando; la principal causa de esto son las prácticas humanas (Primack et al., 2001). Además, se ha generado el conocimiento teórico y la evidencia empírica de que la situación ecológica-territorial actual representa una amenaza para el desarrollo sustentable, para la calidad de la vida humana e incluso para la supervivencia de nuestra especie en el largo plazo.

La comunidad científica se ha interesado e involucrado en las problemáticas inherentes a la degradación ecológica-territorial, en especial las ciencias y disciplinas cercanas a la ecología y las llamadas ciencias ambientales. Una de esas disciplinas científicas es la ecología del paisaje, cuyo surgimiento marca un hito en la historia de la ecología (Forman, 2002). El cuerpo teórico de la ecología del paisaje desempeña un rol cada vez más central en el manejo de los recursos naturales. Según Richard Forman (2002), la ecología del paisaje provee la aproximación más adecuada actualmente para armonizar naturaleza y cultura, por lo que se le puede considerar una de las llamadas ciencias de la complejidad (Naveh, 2000). Uno de los grandes méritos de la ecología del paisaje es su contribución para integrar las ciencias naturales y sociales (Lefeuvre, 2002), y para integrar los distintos campos del conocimiento humano; eso es también uno de los atributos más valiosos del territorio y, especialmente, del paisaje cultural como objetos de estudio. La noción de paisaje cultural corresponde a un concepto innovador y es fundamental para entender las situaciones actuales (Calabuig, 2002), ya que enfatiza la injerencia de la cultura humana sobre nuestra percepción y nuestras acciones en el territorio. El paisaje cultural resulta de la acción humana en el paisaje y se puede considerar un objeto de estudio que integra las diferentes dimensiones inherentes a la coevolución sociocultural y ecológica-territorial, lo que adquiere mayor valor con el origen coevolutivo entre naturaleza y cultura y entre actores sociales y su entorno en la actual degradación ecológica-territorial. En esto además radica el rol fundamental de la transdisciplinariedad en las aproximaciones y propuestas para la sustentabilidad. 
Actualmente los seres humanos vivimos enajenados en tendencias o patrones como la competencia, la apropiación, la producción, entre otras, que nos impiden percibir nuestra responsabilidad en la alteración del entorno y de nuestras vidas (Maturana, 1994). Entre los rasgos y tendencias culturales de nuestra época ha imperado la racionalidad económica (Naredo, 2004), lo que está asociado a la priorización de la dimensión económica por parte de los actores sociales. La imperancia de la racionalidad económica deriva en el dominio y la expansión de paisajes culturales con una funcionalidad primariamente económica, es decir, adecuados para fines y prácticas propios de los manejos económicos actuales.

El presente estudio se centra en el concepto de paisaje cultural y en la problemática de la sustentabilidad ecológica, más precisamente en las relaciones entre la priorización de la dimensión económica por parte de los actores sociales y la estructura del paisaje cultural, y su funcionamiento ecológico. Para esto, se usan especialmente casos y situaciones que suelen ocurrir en el paisaje cultural rural. Se plantea y enfatiza la importancia de la aproximación sistémica y la transdisciplinariedad para el entendimiento integral de la problemática del paisaje cultural y la sustentabilidad. El objetivo es identificar y analizar, con base en los efectos estructurales de la priorización de la dimensión económica en el diseño del paisaje cultural (determinante de orden económico), las principales consecuencias ecológicas de dicha priorización.

\section{Bases teórico-conceptuales: aproximación sistémica, transdisciplinariedad y paisaje cultural}

La geografía y la ecología han recalcado la necesidad de estudiar la naturaleza no en forma sectorial, describiendo procesos aislados, sino que se focalice en visiones sistémicas e integradoras (González, 1981). El concepto sistémico inspiró el desarrollo de un amplio espectro de ciencias aplicadas, incluida la rama holística de ecología ecosistémica desarrollada por E. Odum (Naveh, 2000). Un hito clave fue la creación y difusión de la teoría general de sistemas, la cual se dirige a aspectos de la realidad que hasta su surgimiento eran inasequibles al estudio científico convencional (Bertalanffy, 1975). La aproximación planteada en la teoría general de sistemas ha influido en varios campos científicos. Ejemplos de esto son las orientaciones surgidas en biología, dirigidas a los sistemas abiertos, la equifinalidad y la negentropía, o entropía negativa; o en psicología, reorientándose con base en la comprensión de que la explicación de la conducta humana según la satisfacción de necesidades biológicas y la homeostasis no resulta satisfactoria, ya que no considera ni explica las 
conductas propiamente humanas, es decir, las actividades simbólicas o culturales.

En los últimos 20 a 30 años ha ocurrido lo que se puede considerar la revolución científica posmoderna, fundamentalmente con el surgimiento de las llamadas ciencias de la complejidad (Naveh, 2000). Esto ha significado centrar el estudio en procesos no lineales organizados en redes de interrelaciones jerárquicas, para identificar las principales interacciones entre las variables y procesos involucrados en el objeto de estudio, y así los procesos y tendencias que surgen desde esas interacciones. Para una ecología del paisaje holística, Naveh (2000) plantea como sus bases conceptuales y metodológicas la teoría general de sistemas y la teoría jerárquica. En la organización jerárquica, donde los niveles superiores son espacial (estructuralmente) y temporalmente más constantes que los niveles inferiores, cada nivel más alto adquiere nuevas cualidades emergentes y entonces es más complejo que los niveles inferiores a él. Simon (1962) argumentó de forma convincente que con frecuencia la complejidad toma la forma de jerarquía. En otras palabras, la jerarquía es un componente estructural central de la arquitectura de la complejidad. Puede plantearse que un sistema complejo es un sistema conformado por varios holones organizados en diferentes niveles jerárquicos, lo que implica distintas intensidades de las relaciones entre los elementos del sistema.

La conveniencia de la organización jerárquica para los sistemas complejos es considerable. Para los sistemas biológicos y ecológicos una organización jerárquica tiende a evolucionar con más eficiencia y estabilidad (Simon, 1962; O’Neill et al., 1986). Según la teoría jerárquica, la relación entre dos niveles adyacentes es asimétrica: el nivel superior ejerce restricciones llamadas top-down, que proveen el rol al nivel inferior, mientras que este último provee las condiciones funcionales al superior, llamadas bottom-up. Aunque por la aparente rigidez de estas restricciones (top-down) y fuerzas (bottom-up) puede suponerse que la teoría jerárquica implica inflexibilidad o carencia de creatividad (potencial adaptativo, es decir, adaptabilidad), una adecuada estructura jerárquica y dinámica además de proveer mayor eficiencia y estabilidad provee oportunidades para la diversidad, flexibilidad y creatividad (Wu y David, 2002). Probablemente un sistema complejo no se puede concebir de manera integral y operativa si no es mediante una aproximación jerárquica. En ecología, las jerarquías que construimos resultan de las interacciones entre las características del sistema de estudio (objeto) y el observador que lo estudia (sujeto) (Wu y David, 2002).

La integración de las teorías sistémica y jerárquica ayuda a comprender la aproximación sistémica y su aplicabilidad mediante el desarrollo de aproximaciones operativas. Los dos atributos clave de la aproximación 
sistémica son el estudio contextual e integrado de las variables y procesos involucrados. Se hace notar que desde el surgimiento de la teoría general de sistemas (Bertalanffy, 1968), al sistema se le ha considerado no sólo como un hecho o entidad real o fenoménica, sino que el concepto de sistema ha derivado en un estilo de aproximación epistemológica y ha adquirido el papel de una perspectiva en términos de Bertalanffy (1975) o de un paradigma en términos de Kuhn (1970).

Uno de los atributos clave de la teoría y aproximación sistémica y que la diferencia de la mayoría de las teorías y aproximaciones científicas tradicionales y previas a su surgimiento, es la gran generalidad de su aplicabilidad. Lo anterior está relacionado con paralelismos o isomorfismos entre sistemas y fenómenos variados. Así, por ejemplo, los aspectos genéricos de los sistemas organísmicos son el orden jerárquico, la tendencia hacia una organización de mayor complejidad, la diferenciación en subsistemas, entre otros; sin embargo, tales características se ajustan también a sistemas sociales y económicos. Algo derivado de esto y que constituye uno de los grandes méritos de la perspectiva sistémica, es que ésta permite vencer barreras epistemológicas entre las ciencias y las humanidades, así como entre ambas y los campos tecnoeconómico y político donde actualmente se toman las decisiones sobre el manejo de los recursos naturales (Naveh, 2000; Röling, 2000). El que ocurran esas correspondencias formales entre sistemas es lo que otorga la potencialidad transdisciplinaria a la aproximación sistémica.

Ante la constatación de que la problemática de la degradación ecológica-territorial actual ha sido producto principalmente de la acción humana, es decir, resultante de la coevolución sociocultural y ecológica-territorial, la transdisciplinariedad se constituye en un atributo epistemológico clave para el éxito y la operatividad de las teorías, modelos y aproximaciones dirigidas a dicha problemática. Los estudios para la sustentabilidad han de incorporar integradamente dimensiones y variables ecológico-territoriales y socioculturales, adquiriendo además gran importancia el estudio de las tendencias y prácticas culturales imperantes. Todo lo anterior otorga un valor fundamental al paisaje cultural como objeto de estudio. El paisaje cultural corresponde a la evidencia empírica resultante de la coevolución ecológica-territorial y sociocultural e integra de forma inherente variables de ambos tipos, por lo que es esencialmente transdisciplinario, correspondiendo además a un término polisémico y a un concepto integrador que se puede visualizar y concebir desde diferentes perspectivas y así definirlo de distintas maneras. El concepto de paisaje cultural recalca al factor cultural humano y su injerencia en nuestra percepción y en nuestras actuaciones en el territorio, y así en la interacción con nuestro entorno y en el manejo de los recursos. El paisaje cultural básicamente corres- 
ponde al resultante de la intervención humana en la evolución del paisaje; en términos ecológicos, corresponde a una adecuación del hábitat humano a la expansión de su nicho.

Es interesante hacer notar cierto contraste entre el ecosistema y el paisaje respecto a la significancia cognitiva de ambos. El ecosistema corresponde a un sistema abstracto (sensu Bertalanffy, 1975), ya que no es posible percibirlo directamente desde la observación y su distinción depende de los conceptos incorporados por el sujeto observador; un observador sin incorporación de conceptos de la disciplina ecológica no podrá percibir ni distinguir al ecosistema, y no podrá incorporarlo en su racionalidad ni en sus actuaciones. Un paisaje, en cambio, es un sistema real en términos de Bertalanffy (1975), o concreto en términos de Miller (1975). En efecto, un paisaje se percibe y distingue directamente desde la observación; es decir, para percibir y distinguir el paisaje y así incorporarlo en los procesos cognoscitivos, en la racionalidad y en las actuaciones del sujeto observador no es necesario que éste maneje conceptos de la disciplina ecológica. Relacionado con esto, Naveh y Liberman (1994) han considerado al paisaje como un trozo del mundo real. Respecto a la dimensión perceptual y cognitiva del paisaje, Varela (1993) lo definió como la interfaz entre un organismo y su entorno, lo que recalca al paisaje como regulador de la interacción entre ambos.

Las dos condiciones necesarias para la vida son la adaptación y la autopoiesis $^{1}$ (Maturana y Varela, 1972), por lo que ambos procesos son fundamentales y vitales para la sustentabilidad. En los sistemas vivos, la autopoiesis y la adaptación no ocurren independientemente sino de manera acoplada. El proceso autopoiético ocurre inserto en el contexto definido por el proceso coevolutivo entre cierto organismo y su entorno.

Respecto a la adaptabilidad del paisaje cultural, ésta es limitada y se puede analizar con base en el concepto y modelo de sistema complejo adaptativo de Gell-Mann (1995). Según este autor (1995), los sistemas complejos adaptativos evolucionan de acuerdo con la selección de estados alternativos provenientes del pool de esquemas adaptativos que se ha generado durante la historia evolutiva del propio sistema en interacción con su entorno. Así, las probabilidades de éxito de cierto paisaje en su evolución adaptativa se determinan en gran parte por la similitud entre el tipo, magnitud y tasa de perturbaciones y cambios ocurridos durante su historia evolutiva y por el tipo, magnitud y tasa de perturbaciones y cambios actual y futura. La adaptabilidad del paisaje cultural está condicionada y determinada fundamental y primeramente por el estilo de actuación de

\footnotetext{
${ }^{1}$ Los sistemas como una red de producción de componentes que en sus interacciones generan la misma red de materia, energía e información que los produce y que, por tanto, son capaces de autorreplicarse y autorrepararse se llaman sistemas autopoiéticos (Maturana y Varela, 1972; Naveh, 2000).
} 


\section{Figura I}

\section{Relación e interacción recursiva entre proceso funcional y estructura del paisaje*}

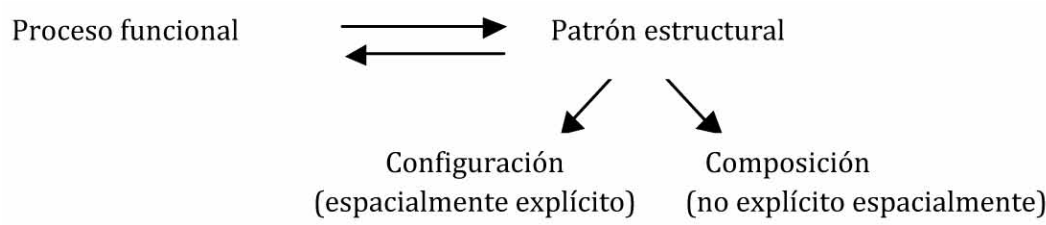

\footnotetext{
* Esta última, según McGarigal y Marks (1995), está constituida por un componente espacialmente explícito (configuración) y otro no explícito espacialmente (composición).

Fuente: Elaboración propia.
}

los actores sociales y por la sociedad en su totalidad, es decir, por el contexto cultural que determina el criterio de selección de estados alternativos para la adaptación y evolución del paisaje cultural.

La dominancia humana sobre el planeta implica que no podemos evadir la responsabilidad de manejarlo de manera activa (Vitousek et al., 1997). Esto recalca la importancia del diseño y la planificación del paisaje cultural. Uno de los principios fundamentales para el diseño y planificación del paisaje cultural, de acuerdo con los planteamientos de la ecología del paisaje, es la relación e interacción recursiva entre proceso funcional y patrón estructural (McGarigal y Marks, 1995; Dramstad et al., 1996); basándose en la estructura del paisaje se deriva respecto a su funcionamiento ecológico. La configuración y la composición se pueden considerar los dos componentes principales de la estructura del paisaje. La configuración corresponde al componente espacialmente explícito de la estructura del paisaje, y la composición corresponde al componente espacialmente no explícito de la estructura del paisaje (McGarigal y Marks, 1995) (figura I).

\section{Racionalidad económica}

Según Aristóteles, la economía consistía en administrar los bienes proveídos por la naturaleza para optimizar su aprovechamiento; en cambio, la crematística consistía en el abastecimiento de los bienes. Uno de los tres tipos de crematística definidos por Aristóteles consistía en adquirir bienes a través del intercambio y del comercio, lo que con la experiencia adquirida por los comerciantes derivó en la manera de conseguir una mayor ganancia propia.

Posterior a la Revolución científica del siglo xviII, la economía fue objeto de un gran reduccionismo, evolucionando con base en una pers- 
pectiva descontextualizada, donde lo económico tendía a reducirse a aquello que es expresable en términos monetarios y que entonces ha de ser apropiable, valorable e intercambiable (Naredo, 1987). En consecuencia, la ciencia económica actual se construyó a partir del desplazamiento del centro de interés desde el mundo físico hacia el universo aislado y descontextualizado de los valores monetarios en el curso de una ruptura epistemológica (esto no implica que no hayan surgido ni actualmente existan tipos o escuelas económicas que intenten diferenciarse de lo anterior), asemejándose esta tendencia económica con el mencionado tipo de crematística definido por Aristóteles. Prácticamente todos los padres de la actual ciencia económica - desde Smith, Ricardo o Marx, hasta Walras, Jevons o Robbins- han insistido en que a la economía no le corresponde ocuparse de lo físico (Naredo y Parra, 1993). La ciencia económica, además, se afianzó con las críticas al planteamiento de los economistas franceses del siglo XviII (hoy llamados fisiócratas) de limitar la producción a las riquezas renovables sin deteriorar los bienes fondo (por ejemplo el suelo fértil). Si la ciencia económica se afianzó con base en aquellas críticas al planteamiento de los fisiócratas, fue porque ello resultó funcional a la ideología y a las prácticas hasta ahora imperantes en la sociedad industrial y posindustrial de nuestra época (Naredo y Parra, 1993).

El reduccionismo según el cual ha evolucionado la economía derivó en prácticas que afectaron la racionalidad subyacente. En la perspectiva de la denominada racionalidad económica, los potenciales de la naturaleza son reducidos a la razón y al capital económicos (Leff, 2002), basándose dicha racionalidad en la maximización de los bienes y utilidades monetarias y en el individualismo metodológico, que actualmente identifica a la economía con el arte del abastecimiento de dinero (Naredo, 1987; Naredo y Parra, 1993). Con el tiempo, la racionalidad económica ha generado formas más sofisticadas de capitalización de la naturaleza que las herramientas propias del mercado, por ejemplo estrategias discursivas (Leff, 2002). La noción de lo económico destaca y predomina actualmente entre las creaciones de la mente humana que otorgan coherencia y racionalidad a su comportamiento (Naredo, 2004). En el presente estudio se plantea la racionalidad económica como una noción subyacente e imperante en nuestra cultura, la cual se refiere fundamentalmente a las nociones y criterios asociados al objetivo prioritario de los actores sociales de maximizar el lucro económico valorable monetariamente en el corto plazo; ${ }^{2}$ así, la racionalidad económica presenta como fuerza motriz la convención social del dinero (Naredo, 2004). Coincidiendo con esta predominancia de lo

\footnotetext{
${ }^{2}$ En adelante, cuando se menciona la racionalidad económica se hace referencia o ese objetivo prioritario por parte de los actores sociales y a las nociones y conceptos asociados a aquello.
} 
económico, Naredo (2004) habla del objetivo generalizado del crecimiento económico, y Verlinde (2002) señala que el criterio económico es el más utilizado para seleccionar el diseño de predios agrícolas.

Durante el periodo de la sociedad industrial, y probablemente como nunca antes en la historia, se consolidó un modelo económico que impera sin contrapartes significativas en prácticamente todo el mundo. Consideremos además la existencia de un fenómeno sistémico que plantea que en los casos en que en un sistema se conservan un conjunto de relaciones particulares por cierto periodo, el resto del sistema cambia en función de esas relaciones que se han conservado (Maturana, 1994). En consecuencia, aunque en distintas magnitudes, la totalidad de la estructura y funcionamiento de la sociedad ha cambiado considerablemente en función de la racionalidad económica y de los conceptos, postulados y prácticas asociadas. Es importante recalcar que no sólo el sistema social se ha organizado en parte en función de la racionalidad económica y el modelo económico imperante, sino que también de cierta manera y en cierto grado el sistema ecológico-territorial.

Existe una importante cantidad de información y datos generados, ya sea empíricamente o con base en modelamiento, los cuales interpretados de forma adecuada respaldan la imperancia de la racionalidad económica como aquí se define. En un estudio acerca de los efectos de las alternativas de prácticas agrícolas sobre el hábitat de vida silvestre en Iowa, se generaron tres escenarios futuros para dos cuencas en estudio, correspondientes a diferentes objetivos prioritarios: un escenario productivo, un escenario de calidad del agua y un escenario de biodiversidad. El primero los autores lo definieron como el escenario futuro más probable si permanece la producción agrícola comercial como el objetivo dominante (prioritario) del manejo del paisaje cultural (Santelmann et al., 2006). Tal percepción de estos autores respecto del escenario cuya primera prioridad era la producción con fines sobre todo comerciales, corresponde justamente a la ocurrencia e imperancia de la racionalidad económica.

En otro estudio, acerca de los conflictos entre manejos económicos y ecológicos en las tierras de pastoreo en Australia, se sondeó con tres paneles de terratenientes la aplicación de principios ecológicos para el manejo de tales tierras y de los paisajes respectivos. Los resultados de dicho sondeo mostraron numerosas barreras económicas para implementar los principios ecológicos por parte de los terratenientes (MacLeod y MacIvor, 2006). Una aproximación más ecológica se consideró desmesurada, costosa y no razonable para proveer beneficios públicos sin una justa compensación, además de inadecuada respecto a la práctica tradicional y comercialmente aceptada (Barr, 2002). Estos resultados se ajustan de manera bastante precisa con los criterios y priorizaciones propios de la racionalidad econó- 
mica referida al objetivo prioritario de maximizar el lucro económicomonetario. Además, esa consideración de que una aproximación más ecológica sería inadecuada respecto a la práctica comercialmente aceptada, corresponde y condice justamente con la imperancia de dicha racionalidad. En la misma publicación se plantea que varios manejadores de tierra privados rechazarían regulaciones y castigos al no lograr los estándares mínimos para la conservación y cuidado ecológico-territorial (MacLeod y McIvor, 2006); esto también es una clara muestra de la priorización de la dimensión económica-monetaria. Es importante hacer notar que ese rechazo a la asignación de responsabilidades y aplicación de regulaciones y castigos no sólo ocurre en actores sociales privados, sino también en importantes dirigentes y en políticas gubernamentales, en Australia (MacLeod y McIvor, 2006) y también en otros continentes y países, por ejemplo en varios gobiernos latinoamericanos.

En el trabajo mencionado acerca de las tierras de pastoreo en Australia, se plantea que la aplicación completa de los principios y criterios ecológicos esbozados en ese estudio requeriría sacrificios económicos empresariales importantes. Otros ejemplos de la transacción entre utilidades económico-monetarias e implementación de principios y criterios ecológicos son los siguientes (MacLeod y McIvor, 2006): el establecimiento de napas freáticas para controlar la salinidad en áreas templadas de pastoreo y cultivo, requeriría cambios significativos en el manejo de la vegetación y el uso de la tierra en el paisaje, incluido un aumento a amplia escala de la cobertura de árboles (Barr, 2000) y la consiguiente disminución de tierra destinada a la producción comercial; se predijeron resultados económicos poco satisfactorios según los parámetros tradicionales para la restricción del uso del fuego en el manejo de pasturas para proteger el hábitat de vida silvestre en el oeste de New South Wales (MacLeod y Noble, 1990), para el control de la salinidad en la zona cerealera del oeste de Australia (Pannell, 1999) y para retener la vegetación nativa en predios de cultivo-ganadería en el noreste de Victoria y en el sur de New South, en Gales (Lockwood et al., 2000). No obstante estas pérdidas económicas, si no se implementan principios y criterios ecológicos, los problemas de disfuncionalidad ecológica de los paisajes quizá aumenten inevitablemente a futuro (MacLeod y McIvor, 2006). Un compromiso serio para adoptar los principios ecológicos implicará una reorientación mayor de los patrones de manejo y de las prioridades en las empresas y sus manejadores (MacLeod y McIvor, 2006), así como de los actores sociales en general.

Otro rasgo de la racionalidad económica es la competitividad, lo que también presenta implicaciones ecológico-territoriales ya que la competitividad opera contra la cooperación y acción colectivas, y éstas son de 
gran importancia para lograr metas que requieren importantes esfuerzos y costos, que sean de largo plazo y concernientes a cuestiones comunitarias. Una muestra de esa tendencia alejada de la acción colectiva es la disposición que los grupos de terratenientes australianos mostraron para acciones ecológicamente sustentables y realizar el trabajo correspondiente de manera colectiva, la cual no fue mayor que la disposición a nivel individual (MacLeod y McIvor, 2006).

Las prácticas de manejo asociadas a la racionalidad económica, por ejemplo la intensificación de la producción agrícola con fines sobre todo comerciales y la consiguiente tecnologización, tampoco se han mostrado solventes económica y financieramente. Ejemplificando lo anterior, en un estudio de tres áreas rurales de Finlandia se relacionaron los cambios del paisaje con la modernización agrícola durante aproximadamente los últimos 40 años del siglo pasado, y una de las observaciones en ese estudio fue que un promedio de $66 \%$ de los predios en las tres áreas estudiadas (2,204 predios en total) desistió de la producción agrícola durante el periodo estudiado (Hietala-Koivu, 2002). Lo anterior muestra claramente que la intensificación agrícola de las últimas décadas no ha implicado sostenibilidad ni estabilidad económica-financiera.

En Latinoamérica también existen varios casos que se pueden mencionar como ejemplos de que se ha dado la racionalidad económica en el manejo ecológico-territorial y de recursos naturales. Uno de estos casos es el de la industria forestal chilena, el cual ha sido extensamente estudiado en la literatura académica y científica, y fue abordado de manera integral por Erlwein et al. (2008). El gran crecimiento de esta industria, que se explica principalmente por la gran expansión territorial de las plantaciones forestales desde mediados de los años sesenta hasta fines de los noventa y por el aumento de las plantas productoras y de la producción de pulpa de celulosa, ha provocado efectos y se asocia a fenómenos pertinentes de hacer notar respecto a los objetivos del presente trabajo: se ha promovido sistemáticamente el crecimiento ilimitado, por definición contrario a la sustentabilidad; aumento de la superficie destinada a la producción intensiva; producción a una escala excluyente; disminución de los parches hábitat nativos y de la bio y ecodiversidad, alejándose del concepto de uso múltiple del territorio; deterioro de recursos productivos; concentración del capital e inequidad socioeconómica; desequilibrios territoriales; homogenización del paisaje cultural; falta de consideración de la diversidad cultural, contraria a una ética de la otredad; entre muchos otros. Finalmente, ha sido un crecimiento sectorial que no ha incorporado dimensiones distintas a la económica-monetaria (como histórica, social, ecológica, etc.) ni objetivos distintos a los propios y particulares de los 
actores sociales que han manejado el proceso, y por consiguiente no ha propiciado un desarrollo territorial integral.

Margalef (1998) plantea que la transmisión cultural puede ser perjudicial si crece exponencialmente y se difunden en exceso algunas formas de comportamiento. Esa transmisión cultural exponencial y excesiva puede potencialmente perjudicar a la sociedad o agrupación respectiva, pero sólo si dicha transmisión cultural deriva en adoptar tendencias y rasgos culturales que tienden a la exclusión o inhibición de otros comportamientos.

Aunque la racionalidad económica se ha contrapuesto a cambios en las prácticas y manejos asociados a su imperancia (Leff, 2002), parece factible que estos cambien en el mediano plazo. Según MacLeod y McIvor (2006), son clave los resultados deseados y los usos de los recursos del paisaje por parte de la comunidad, cambiar los derechos de propiedad, y adecuar los roles reguladores de los mercados y la institucionalidad para lograr un balance aceptable entre imperativos económicos y ecológicos (MacLeod y McIvor, 2006). Es decir, antes que cambios políticos, institucionales y legislativos, se requiere un cambio de las visiones de la comunidad, lo que corresponde a un cambio cultural y es la base para los demás cambios, ya que genera las condiciones para que estos ocurran, se sustenten y perduren. Se hace notar que al comienzo de esta sección se definió la racionalidad económica como una noción subyacente imperante en nuestra cultura.

A continuación se plantean algunos principios propios y característicos de la racionalidad económica, en el sentido que aquí se ha definido. Es pertinente aclarar que no se plantea que estos sean los únicos principios propios y característicos de la racionalidad económica, y tampoco que estos sean los más importantes e identificatorios; sólo se plantean como principios válidos respecto a la racionalidad económica y concernientes y operativos para la aproximación y objetivos del presente estudio. Algunos de estos principios ya se mencionaron o insinuaron antes. Es importante recalcar que estos principios se deben considerar e interpretar conjunta e interrelacionadamente, es decir, no de forma individual ni aislada, ya que así adquieren mayor coherencia y validez. Considerarlos e interpretarlos individual y aisladamente correspondería a una aproximación merológica, contraria a la aproximación sistémica que se plantea y enfatiza en el presente trabajo. Los principios surgen desde las mismas bases conceptuales y además se integran y complementan operacionalmente, por lo que ocurre cierto traslape o sobreposición entre ellos, lo que otorga solidez al planteamiento total. ${ }^{3}$

\footnotetext{
${ }^{3}$ Cada uno de los principios que se enunciarán en cursivas en el presente artículo han sido retomados de Subercaseaux (2007), tanto los que están comprendidos en el capítulo 2 los principios de la racionalidad económica y en el apartado 3.1 principios propios del determinante del orden económico.
} 
Principio poiético: El valor de las cosas y de las acciones radica fundamental y principalmente en su producto. Este principio se refiere a la poiesis en sentido aristotélico, la cual significa acción valiosa por y según su producto. Esto es contrario a la praxis en sentido aristotélico, que significa acción valiosa por sí misma independientemente de su resultado o producto. Es característico y propio de la racionalidad económica una priorización del producto por encima de la acción en sí misma. Según Murray Gell-Mann (1995), premio Nobel de Física, la historia ha mostrado claramente que la humanidad ha progresado no gracias a aquellos que a cada paso miden el éxito o fracaso final de sus aventuras, sino a quienes piensan profundamente en lo que es justo y luego se esfuerzan en alcanzarlo. Esto enfatiza la importancia de una racionalidad y actitud diferentes y a veces contrarias a lo que plantea el principio poiético.

Principio de la enajenación: Se debe evitar el ocio e intensificar las acciones hacia uno o más objetivos. Según Aristóteles, el hombre tiene ocio y negocio, pero ambos se contraponen. Una consecuencia de la enajenación es la alteración del curso natural de algo. Efectos importantes de la enajenación son cierta confusión, pérdida de responsabilidad por los propios actos y de creatividad. Dicha pérdida de responsabilidad es especialmente importante respecto de la situación y degradación ecológica-territorial. Max Neef (1994) plantea que el ocio es muy positivo y que está asociado al potencial creativo y, así, al desarrollo humano.

Principio de la competitividad: Se debe competir y rivalizar para la consecución de uno o más objetivos. Como dice Naredo (2004), la competitividad en gran medida rige lo económico. La competencia y rivalidad a que se hace referencia, ocurre especial y más intensamente frente a planteamientos y acciones contrarios a los objetivos propios e inconvenientes para estos. El beneficio individual no necesariamente deriva en el beneficio colectivo. Más aún, como se muestra más adelante, la excesiva priorización del beneficio individual deriva en un perjuicio colectivo, es decir, es negativa para el sistema total.

Principio del individualismo: Se debe actuar con independencia de las situaciones, planteamientos y acciones ajenas. Este principio está muy relacionado con el principio de la competitividad. Es importante aclarar y enfatizar que la independencia a la que se hace referencia, se relaciona y deriva en la priorización de los planteamientos y objetivos propios y particulares.

Principio de la apropiación: Para el progreso hacia cierto fin y el logro de ciertos objetivos, es debido y conveniente adueñarse de los recursos necesarios y adecuados para ello y aplicar los medios convenientes para la consecución de tales objetivos particulares. Este principio se relaciona muy de cerca con 


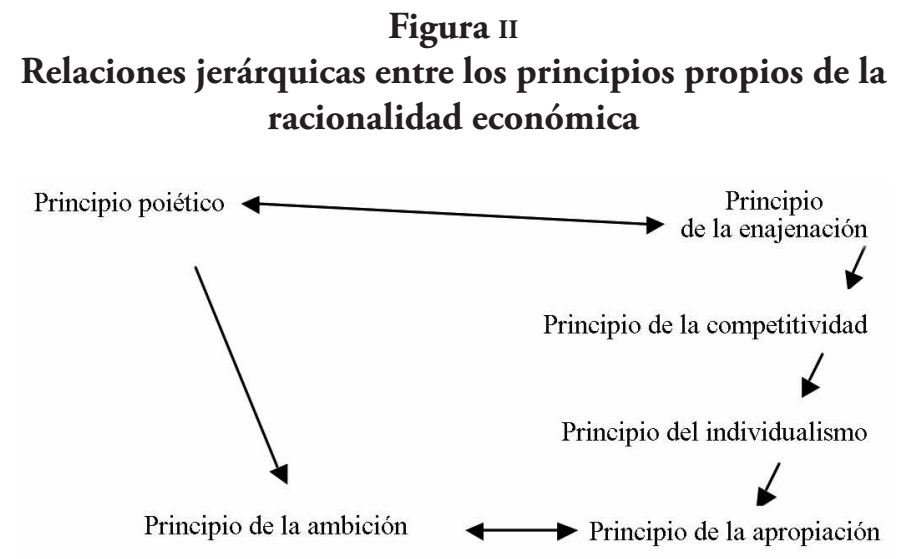

Fuente: Elaboración propia.

el del individualismo. Algo de gran importancia para el presente estudio, es que la apropiación implica exclusión y deriva en ella.

Principio de la ambición: Es debido y conveniente actuar afanosamente en función y hacia la obtención de riqueza material y poder. Este principio es bastante claro. Es importante hacer notar, especialmente para los objetivos del presente estudio, que ese afanoso actuar en función y hacia la consecución de riqueza material y poder suele derivar en que estos se dejan de considerar medios, y se consideran fines u objetivos en sí mismos.

En la figura II se muestran las relaciones jerárquicas existentes entre los principios propios y característicos de la racionalidad económica recién planteados.

Los resultados y conclusiones teóricas y de la simulación computarizada de un estudio en que se analizó la interacción entre sistemas dinámicos económicos y ecológicos, sugieren que situaciones altamente competitivas con maximización de la ganancia individual provoca una lucha por la supervivencia entre los jugadores que necesitan esos recursos para su bienestar (Scheffran, 2000). El alto grado de competencia es propio de la situación que genera la racionalidad económica, como lo plantea el principio de la competitividad y más indirectamente el principio del individualismo. En el mismo estudio se concluye que la cooperación para distribuir el capital conduciría a un uso más sustentable de los recursos naturales, y que para la mutua tendencia sustentable los actores sociales necesitan adaptar sus acciones entre sí (Scheffran, 2000), optimizando la condición colectiva. Lo anterior es contrario a lo que plantean todos los principios propios de la racionalidad económica y sus consecuencias. 


\section{Determinante de orden económico}

Este concepto se refiere a la priorización, por parte del actor social, de alguna de las dimensiones involucradas inherentemente en el diseño y manejo del paisaje cultural. Al cambiar la priorización y así la importancia relativa de alguna de esas dimensiones, cambia el determinante de orden. Se plantean como dimensiones fundamentales la ecológica, la social y la económica, y entonces a los determinantes de orden ecológico, social y económico con los fundamentales en el diseño y manejo del paisaje cultural.

Como se dijo, la racionalidad económica ha sido una tendencia cultural imperante en la sociedad industrial y posindustrial. Por esto, la antropización y artificialización del paisaje cultural en dicho periodo, y así su diseño y manejo, han sido determinados fundamentalmente por factores y condicionantes propios y atribuibles a la dimensión económica. El determinante de orden económico es la expresión de la racionalidad económica en el paisaje cultural. Esto resulta en la predominancia relativa de los servicios económicos respecto de los servicios ecológicos (ecosistémicos) y sociales. Una consecuencia directa de esto último es el deterioro de la funcionalidad ecológica y social del paisaje cultural. A su vez, una consecuencia más indirecta es el aumento de las probabilidades de que ocurran enfermedades ecosistémicas (por ejemplo, erosión, disminución de biodiversidad, contaminación del agua, desertificación, etcétera).

\subsection{Principios propios del determinante de orden económico}

Para idear los principios propios y característicos del determinante de orden económico se realizó un estudio observacional y de paisajes culturales rurales correspondientes a predios agrícolas de la zona central de Chile, donde se realiza alguna actividad productiva con fines económico-monetarios, de forma complementaria se analizan los resultados de una entrevista previamente diseñada en función de los objetivos del estudio y hecha a actores sociales que manejan predios agrícolas. Se realizaron observaciones respecto a temas como los siguientes: manejo de desechos productivos contaminantes; incorporación de vegetación con fines no comerciales; motivaciones asociadas a las consideraciones de tipo estético y ecológico; importancia otorgada a la implementación tecnológica; percepción de la relación entre naturaleza y actividad agrícola productiva; especialización/ diversidad predial; diseño, manejo y planificación predial integral o fragmentada; limitantes desde contexto (entorno) territorial a manejos diferentes a los imperantes; capacidad de respuesta del predio; prioridades en 
el manejo y motivaciones asociadas a ellas, entre otros. Las observaciones realizadas después se analizaron e interpretaron en profundidad.

Además se revisaron y reinterpretaron varias investigaciones previas disponibles en la literatura (especialmente científica) sobre la evolución de paisajes culturales, por ejemplo el estudio mencionado en que se describieron los cambios de los paisajes de tres regiones rurales de Finlandia entre los años 1954 y 1998, relacionándolos con la modernización agrícola, para lo cual se usaron índices de su estructura. El estudio muestra una disminución de la heterogeneidad del paisaje, lo que deriva de la concentración del uso de la tierra en parches productivos y predios más grandes y de la disminución del largo y densidad de borde (Hietala-Koivu, 2002). En otro estudio se evaluó el cambio en el patrón del paisaje agrícola y en la sustentabilidad ecológica a escala local, entre 1980 y 2000 en la región montañosa de Loess, en Ansai, China. Con base en mapas de uso de la tierra se establecieron ocho tipos de paisaje y se usaron 14 variables que describen su estructura. Una de las principales conclusiones del estudio es que valores altos de complejidad de forma de parches se asocian a paisajes de alta sustentabilidad ecológica (Fu et al., 2006). Observaciones y conclusiones pertinentes para el presente trabajo entregaron dos estudios en distintas zonas de Finlandia en que se analizaron los cambios del paisaje agrícola, uno de ellos basado en sistemas de información geográfica (sIG) (Ruuska y Helenius, 1996; Hietala-Koivu, 2002), además de otro estudio acerca del impacto de la intensidad de producción en la generación de servicios ecosistémicos en los paisajes agrícolas en Suecia (Bjorklund et al., 1999). Estos fueron algunos de los estudios revisados.

Todo lo anterior se analizó y discutió iterativamente con estudiosos y profesionales vinculados a estas temáticas (ordenación territorial, diseño y planificación del paisaje, administración económica, etc.), además se consideraron teorías, modelos y conceptos avalados por la ciencia.

Al igual que con los principios propios de la racionalidad económica, no se plantea que estos sean los únicos principios propios y característicos del determinante de orden económico, y tampoco que sean los más importantes e identificatorios; sólo se plantean como principios válidos respecto al determinante de orden económico y concernientes y operativos para la aproximación y objetivos del presente estudio. Además, se aclara que aquí no se plantea que durante el diseño prioritariamente económico del paisaje los actores sociales se guíen por estos principios o se esmeren en aplicarlos, más bien se hipotetiza que los paisajes resultantes de una priorización económica en su diseño serán acordes con los principios propios del determinante de orden económico que aquí se postulan. Como se verá, algunos de estos principios ya se mencionaron o insinuaron antes. En algunos enunciados o explicaciones de los princi- 
pios se hace referencia a diferentes clases que constituyen el paisaje cultural. Dichas clases corresponden a los distintos tipos de parches (unidades espaciales) que constituyen el paisaje cultural; así, según lo planteado, se considera a los tipos de parches y clases económica, ecológica y social. $\mathrm{Al}$ igual que los principios propios de la racionalidad económica, estos principios adquieren mayor coherencia y validez al considerarlos e interpretarlos de manera conjunta e interrelacionada (aproximación sistémica), es decir, no individual ni aisladamente (aproximación merológica). Los principios se integran y complementan de forma operacional, por lo que ocurre cierto traslape o sobreposición entre ellos, lo que otorga solidez al planteamiento total.

Los principios corresponden a diferentes niveles jerárquicos, y en ese orden se presentan. Los principios relacionados con el nivel axiomático son postulados fundamentales de la jerarquía de principios. Los principios correspondientes al nivel técnico se refieren a modos estratégicos de manejo que otorgan mayor eficacia y eficiencia al determinante de orden económico, es decir, al diseño del paisaje cultural con fines prioritariamente económico-monetarios. Los principios que tienen que ver con el nivel del paisaje cultural son aquellos que, ante la ocurrencia del determinante de orden económico, suceden y se expresan en la totalidad del paisaje. Los correspondientes al nivel de clase económica son principios que, ante la ocurrencia del determinante de orden económico, se dan y expresan en la porción del paisaje correspondiente a la clase económica, o sea, en los parches correspondientes a dicha clase.

\subsubsection{Principios axiomáticos}

Principio utilitario: Los recursos deben ser utilizados hasta la máxima magnitud posible.

Principio de la eficiencia: La eficiencia debe ser máxima de acuerdo a los recursos disponibles.

\subsubsection{Principios técnicos}

Principio tecnologista: La implementación tecnológica debe considerarse positiva y conveniente para la utilización de los recursos y la artificialización del paisaje hasta la magnitud más rentable y asi más lucrativa económicamonetariamente.

Principio de la especialización: La actividad económica debe especializarse para optimizar el manejo administrativo económico, satisfaciendo las demandas y tendencias del mercado y maximizando la rentabilidad y asi el lucro económico-monetario. 
La validez e intensidad de ocurrencia de este principio aumenta con el incremento del capital involucrado: con mayor capital, mayor es la complejidad administrativa y con eso mayor es la necesidad de especialización para simplificar y facilitar el manejo de esa complejidad. Es importante hacer notar que los principales factores determinantes del grado de especialización en el determinante de orden económico son las demandas y tendencias del mercado y la rentabilidad económica, y no las características ecológicas de las diferentes unidades espaciales que componen el paisaje correspondiente.

\subsubsection{Principios a nivel de paisaje cultural}

Principio de la rentabilidad: Los bordes de las unidades espaciales deben coincidir con el diseño del paisaje más rentable y asi más lucrativo económica-monetariamente. Es importante precisar que este principio propio del determinante de orden económico no considera los bordes naturales del paisaje; es decir, al diseñar el paisaje cultural y ubicar y delimitar las unidades espaciales que lo conforman, se debe considerar sólo la maximización de la rentabilidad y del lucro económico-monetario y ningún otro tipo de consideración.

Principio de la artificialización: El paisaje debe ser transformado mediante técnicas y la implementación tecnológica hasta la magnitud más rentable y asi más lucrativa económica-monetariamente. Este principio se relaciona cercanamente con el de la rentabilidad y también con el tecnologista. Un corolario inmediato del principio de la artificialización y de gran importancia para este estudio, además de ser un efecto generado conjuntamente con el principio de la rentabilidad, es que para decidir respecto a la implementación tecnológica no se considera la receptividad tecnológica del ecosistema.

Principio de la exclusión: La superficie relativa destinada a actividad económica debe tender hacia la superficie total, en función de maximizar la rentabilidad y así el lucro económico-monetario. Respecto a este principio, se hace notar que la expresión máxima del determinante de orden económico correspondería a la ausencia total de parches correspondientes a otra clase, como la ecológica y la social.

\subsubsection{Principios a nivel de clase económica}

Principio de la conectividad y circuitería: La eficacia y eficiencia de las conexiones entre los parches correspondientes a la clase económica debe ser la máxima posible. La eficacia y eficiencia de las conexiones entre los parches correspondientes a la clase económica están determinadas primero por la 
conectividad, esto es, por el grado al cual todos los parches correspondientes a dicha clase están espacial y funcionalmente ligados, y de forma secundaria por la circuitería, o sea, por el grado en que se presentan rutas alternativas. Se aclara y recalca que, ante la ocurrencia del determinante de orden económico, la máxima eficacia y eficiencia posible de las conexiones entre los parches correspondientes a la clase económica se establece y se determina sólo por factores económicos, o sea, por factores que afectan y condicionan la rentabilidad económica y así al lucro económico-monetario. Es decir, factores de otra índole y que afectan otras dimensiones, como la ecológica y la social, no se consideran. Esta aclaración y énfasis se hacen en varios de los siguientes principios.

Principio de la intensificación: La superficie relativa destinada a producción comercializable intensiva debe tender hacia la superficie total. Éste se relaciona muy de cerca con el principio de la artificialización, conjuntamente con el principio de la exclusión.

Principio de la monoprodutividad: La diversidad de los parches correspondientes a la clase económica debe estar determinada y condicionada por la maximización de la rentabilidad y asi del lucro económico-monetario en función principalmente de las demandas y tendencias del mercado. Este principio adquiere validez e importancia especialmente con la consideración e interpretación integrada de algunos principios anteriores, sobre todo los de la especialización, la rentabilidad y la artificialización. El principio de la especialización plantea explícitamente la simplificación de la administración económica; además los principios de la rentabilidad y de la artificialización derivan en una alta productividad con fines económico-monetarios mediante un paisaje transformado (artificializado) tecnológicamente. Para complementar todo aquello con el enunciado del principio de la monoproductividad, resulta en un paisaje simple y homogéneo, con alta producción comercial y diseñado con base en la implementación tecnológica para satisfacer las demandas del mercado económicamente más rentables y así más lucrativas. Todo lo anterior derivará en que la diversidad productiva sea bastante baja, tendiendo muchas veces a la monoproducción y así a un solo uso del suelo.

Principio de la escala espacial: Los parches correspondientes a la clase económica deben ser del mayor tamaño posible. Este principio está muy relacionado con el principio de la exclusión, y también con el de la mínima cantidad. La conveniencia de niveles productivos mayores y de unidades espaciales correspondientes a la clase económica de mayor tamaño, radica en el concepto de economía de escala, originado en la disciplina de la economía productiva. Al igual que para el principio de la conectividad y circuitería, se recalca que ante la ocurrencia del determinante de orden económico, el máximo tamaño posible de los parches 
correspondientes a la clase económica se establece y se determina sólo por factores económicos, o sea, por factores que afectan y condicionan al lucro económico-monetario.

Principio de la minima cantidad: La cantidad de parches correspondientes a la clase económica debe ser la minima posible, considerando el potencial y costos productivos en los distintos ámbitos territoriales y el manejo del riesgo económico. Una cuestión importante de notar acerca de este principio es que, aunque por el manejo del riesgo (por ejemplo, control de un foco de enfermedad en un cultivo agrícola) es conveniente que existan varios parches correspondientes a la clase económica, los paisajes en los cuales ocurre el determinante de orden económico se suelen diseñar minimizando el número de parches correspondientes a esa clase. Aunque el riesgo es un factor de alta importancia, cuando se diseñan los paisajes culturales con priorización económica-monetaria suele sobreponerse el principio de exclusión y el concepto de economía de escala a la consideración del riesgo. Lo anterior quizá está relacionado con la falta de consideración espacial en la economía y con el escaso desarrollo al respecto en la teoría y en los modelos económicos. Se enfatiza que la mínima cantidad posible de los parches correspondientes a la clase económica se establece y se determina sólo por factores económicos, o sea, por factores que afectan y condicionan el lucro económico-monetario.

Principio del contagio: Los parches correspondientes a la clase económica, especialmente aquellos correspondientes a una misma especialización económica, deben ubicarse lo más agrupados y contiguos posibles. El contagio se refiere a la interspersión o entremezcla de los diferentes tipos de parches (clases) y a la dispersión o distribución espacial del tipo de parche respectivo (clase respectiva) (McGarigal y Marks, 1995), en este caso la económica. Es decir, el enunciado del principio del contagio plantea que ante la ocurrencia del determinante de orden económico, el contagio de la clase económica sería alto. Para clarificar más el concepto de contagio, y cómo éste se expresa en el paisaje, un ejemplo: valores de contagio mayores resultarán de paisajes con pocos parches grandes y contiguos, mientras que valores de contagio menores resultarán de paisajes con varios parches pequeños y dispersos (McGarigal y Marks, 1995). Este principio del contagio deriva principal y más directamente del principio de conectividad y circuitería. Es importante hacer notar que este principio es una integración bastante completa de los patrones propios y característicos del paisaje cultural resultante del determinante de orden económico, por lo que se relaciona fuertemente con la mayoría de los principios propios de ese determinante de orden aquí planteados (figura III), y sería un adecuado indicador de su ocurrencia. El hecho de que el mayor contagio en los parches correspondientes a la clase económica suceda en los parches 
correspondientes a una misma especialización económica, se explica y deriva sobre todo del principio de la especialización. Se destaca que el máximo agrupamiento y contigüidad posible entre los parches correspondientes a la clase económica, son establecidos y determinados solo por factores económicos, o sea por factores que afectan y condicionan al lucro económico-monetario.

Principio de la minima distancia: La distancia entre los parches correspondientes a la clase económica, especialmente aquellos correspondientes a una misma especialización económica, debe ser la minima posible.

Este principio deriva directamente del principio del contagio. Al igual que en este último, el que la mayor intensidad de ocurrencia de la mínima distancia entre los parches correspondientes a la clase económica ocurra en los parches correspondientes a una misma especialización económica, se explica y deriva sobre todo del principio de la especialización. Se enfatiza además que la mínima distancia posible entre los parches correspondientes a la clase económica se establece y se determina y condiciona sólo por factores económicos, o sea, por factores que afectan y condicionan el lucro económico-monetario.

Principio de la geometrización: Las formas de los parches correspondientes a la clase económica y de las unidades espaciales contiguas a estos deben ser lo más simples posibles. En general, esa simplicidad de las formas de los parches correspondientes a la clase económica y de las unidades espaciales contiguas a estos, tiende a resultar en una forma geométrica rectilínea. Se resalta que la máxima simplicidad posible de los parches correspondientes a la clase económica y de las unidades espaciales contiguas a estos se establece y determina sólo por factores económicos, o sea, por factores que afectan y condicionan el lucro económico-monetario.

Principio de la contigüidad: Los parches correspondientes a la clase económica, especialmente aquellos correspondientes a una misma especialización económica, deben presentar la máxima contigüidad posible. El hecho de que la mayor intensidad de ocurrencia de la contigüidad entre los parches correspondientes a la clase económica sea en los parches correspondientes a una misma especialización económica, se explica y deriva sobre todo del principio de la especialización. Se recalca que la máxima contigüidad posible entre los parches correspondientes a la clase económica se establece, determina y condiciona sólo por factores económicos, o sea, por factores que afectan y condicionan al lucro económico-monetario.

En la figura III se muestran de manera más precisa, explícita y gráfica las relaciones jerárquicas entre los principios propios y característicos del determinante de orden económico recién planteados, así como la intensidad o cercanía de esas relaciones. Es importante hacer notar que el vínculo que asocia a los principios utilitario y tecnologista con los principios de 


\section{Figura III}

\section{Relaciones jerárquicas entre lo principios propios del determinante de orden económico}

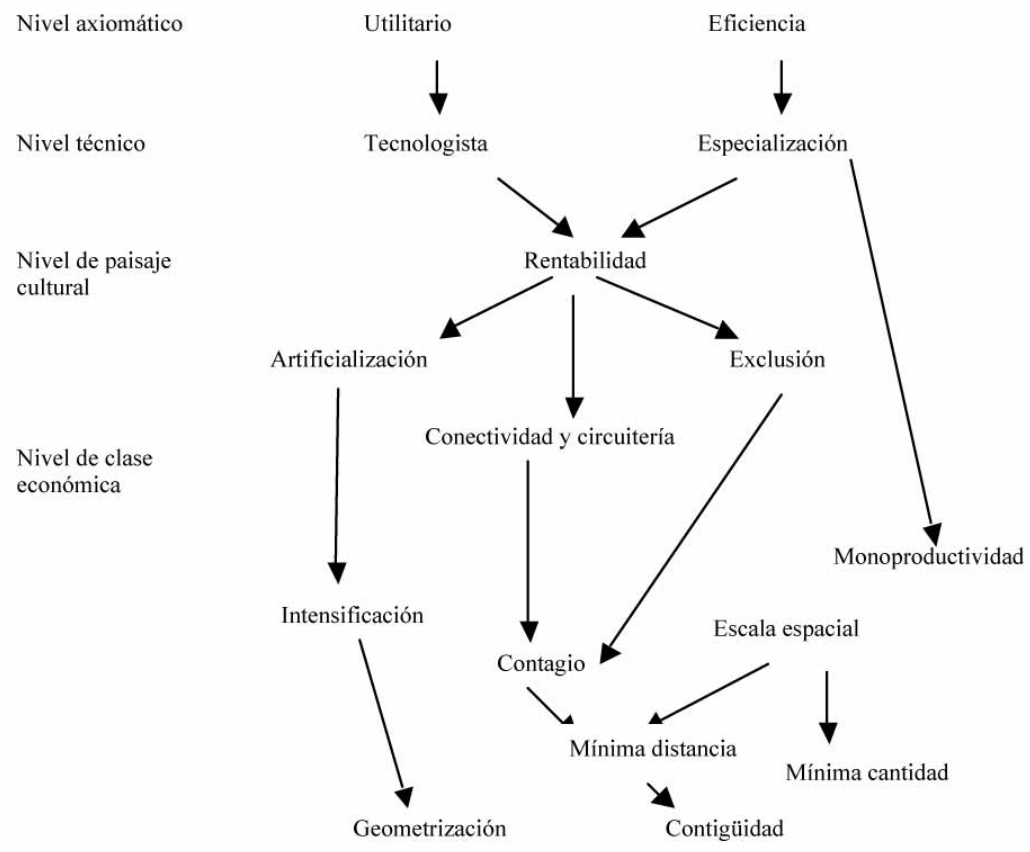

Fuente: Elaboración propia.

eficiencia y especialización es el principio de la rentabilidad, que dice que los lindes de las unidades espaciales deben coincidir con el diseño del paisaje más rentable y asi más lucrativo económica-monetariamente. Estos principios y las cuestiones planteadas se seguirán usando más adelante.

\section{Consecuencias ecológicas del determinante de orden económico}

Este tipo de consecuencias se refieren a las implicaciones y efectos de la priorización de la dimensión económica en el diseño del paisaje cultural sobre su estructura, y así sobre su funcionamiento ecológico. Dichas consecuencias ecológicas derivan de la transacción entre funcionalidad económica y ecológica en el paisaje cultural, lo que a su vez resulta en una transacción entre la magnitud de la generación de servicios económicos y la magnitud de la generación de servicios de otros tipos, por ejemplo ecológicos (ecosistémicos). Con la optimización del manejo administrativo económico, se intensifica la transacción entre los funcionamientos económico y ecológico, es decir, se intensifica la interacción y el efecto 
mutuo entre los componentes y operadores económicos y ecológicos. Ciertas tendencias y carencias de la ciencia económica han acrecentado las consecuencias ecológicas del determinante de orden económico. Constanza et al. (1997) afirmaron que la integración de economía y ecología está obstaculizada por la falta de consideración del espacio en las teorías y modelos económicos.

Algunos estudios han establecido y reportado las consecuencias de la priorización económica en el manejo ecológico-territorial en casos puntuales a diferentes escalas. Presiones excesivas sobre el paisaje, producto de la priorización económica, provocarían una disfunción ecosistémica en la manera en que el paisaje mantiene, utiliza y regenera recursos, con consecuencias negativas para la constante generación de servicios ecológicos (MacLeod y McIvor, 2006). Estos autores plantean la importancia de mantener la presión sobre el paisaje dentro de los límites requeridos para un funcionamiento ecosistémico equilibrado, lo que es clave para lograr un manejo de la tierra ecológicamente sustentable. Por desgracia, con frecuencia esos límites se exceden. En el caso de las empresas de pastoreo de Australia, las innovaciones y manejos motivados por la producción y la rentabilidad y el lucro económico de la actividad ganadera en el corto plazo, pueden llevar a varias formas de disfunción del paisaje cultural, entre otros: disminución de la productividad de pasturas nativas y sembradas; reducción de la tolerancia de las pasturas a la sequía; acidificación de los suelos, salinización y deterioro de su estructura y aumento de la erosión; salinización del agua y eutrofización de cursos de agua y lagos; disminución de los árboles a escala de paisaje cultural; pérdida de importantes especies vegetales y animales, local y regionalmente; invasión de hierbas nativas y exóticas; pérdida de opciones de usos futuros de la tierra (por ejemplo, ecoturismo, investigación científica, etc.); pérdida de valores de amenidad (calidad de vida) de la ruralidad (MacLeod y McIvor, 2006).

El escenario prioritariamente productivo-comercial que se generó en el estudio mencionado acerca del efecto de las prácticas agrícolas en dos cuencas de Iowa, el cual los autores describieron y percibieron como el más probable, corresponde a un adecuado ejemplo descriptivo del paisaje resultante del determinante de orden económico y presenta varias consecuencias. Los resultados negativos de ese escenario para la vida silvestre que se establecen en ese estudio son las siguientes: todas las taxas y la generalidad de los vertebrados nativos pierden hábitat en ambas cuencas, excepto los mamíferos, para los cuales el hábitat permanece estable debido a prácticas conservacionistas de cultivos en hileras, proveyendo mayor cobertura a los pequeńos mamíferos que las prácticas de labranza convencionales; el hábitat para las especies introducidas permanece más o menos igual, mientras que para las especies raras el hábitat disminuye 
en ambas cuencas (Santelmann et al., 2006). Lo anterior es un ejemplo en la literatura científica de las consecuencias de la racionalidad económica y del determinante de orden económico sobre el hábitat para la fauna y flora silvestres.

Para establecer las consecuencias ecológicas genéricas -es decir, no casuísticas- del determinante de orden económico, se establecieron los aspectos y variables básicas que debieran considerarse. Para aquello se establecieron y precisaron las principales propiedades y variables descriptivas de la estructura del paisaje y que han de considerarse en su análisis, las cuales se muestran en el cuadro 1 . Se hace notar que el cuadro 1 es una pauta útil y aplicable para describir cualquier fenómeno, proceso o efecto estructural en el paisaje, y también es útil como base para interpretar sus consecuencias ecológicas.

Relacionando los principios propios del determinante de orden económico con las propiedades y variables estructurales del paisaje que se indican en el cuadro 1 , se establecieron las principales consecuencias de la ocurrencia del determinante orden económico sobre la estructura del paisaje. Tales efectos estructurales se presentan ordenados sobre todo de acuerdo con la jerarquía de los principios propios del determinante de orden. Aunque algunos efectos estructurales parezcan redundantes entre sí, igualmente se explicitarán para facilitar su aplicación. Además, se precisa la significancia ecológica de cada uno de esos efectos y tendencias estructurales del paisaje cultural. Esas consecuencias ecológicas ocurren especial y principalmente en el largo plazo y, en general, es en esa escala temporal cuando se expresan en el paisaje, lo que se recalca de forma repetida y sistemática. Después, con base en la interpretación ecológica conjunta de esos efectos y tendencias estructurales en el paisaje cultural, se precisarán ciertas consecuencias ecológicas más generales del determinante de orden económico.

Es importante aclarar que los parches correspondientes a la clase económica que presentan vegetación (por ejemplo, cultivos agrícolas, plantaciones forestales) constituyen parches hábitat, aunque estos presenten una calidad como hábitat considerablemente menor que los parches correspondientes a la clase ecológica. Además, parches que presenten una especialización económica similar, pero no igual, constituyen hábitats distintos. Por ejemplo, dos parches de producción frutal intensiva con diferentes especies frutales, presentarán distinta composición biológica (por ejemplo, diferentes especies de insectos). Esto recalca que los parches correspondientes a la clase económica también deben considerarse en el diseño del paisaje dirigido a la sustentabilidad de la generación de servicios ecológicos. 


\section{Cuadro 1 \\ Aspectos, propiedades y variables estructurales del paisaje}

\begin{tabular}{|c|c|c|}
\hline Aspectos & Propiedades & Variables \\
\hline \multirow[t]{2}{*}{ Cantidad (parche y clase) } & \multicolumn{2}{|l|}{ Número absoluto (clase y paisaje) } \\
\hline & \multicolumn{2}{|l|}{ Densidad de parches (clase y paisaje) } \\
\hline \multirow{3}{*}{$\begin{array}{l}\text { Tamaño (parche, clase } \\
\text { y paisaje) }\end{array}$} & \multicolumn{2}{|l|}{ Tamańo absoluto (clase y paisaje) } \\
\hline & \multicolumn{2}{|l|}{ Tamańo medio (clase y paisaje) } \\
\hline & \multicolumn{2}{|l|}{ Variabilidad de tamaño (clase y paisaje) } \\
\hline \multirow{3}{*}{$\begin{array}{l}\text { Forma (parche, clase } \\
\text { y paisaje) }\end{array}$} & \multirow{3}{*}{$\begin{array}{l}\text { Complejidad de forma (parche, clase } \\
\text { y paisaje) }\end{array}$} & Absoluta \\
\hline & & Media \\
\hline & & $\begin{array}{l}\text { Media ponderada } \\
\text { por área }\end{array}$ \\
\hline \multirow{7}{*}{$\begin{array}{l}\text { Borde (parche, clase } \\
\text { y paisaje) }\end{array}$} & \multicolumn{2}{|l|}{ Largo de borde (parche, clase y paisaje) } \\
\hline & \multicolumn{2}{|l|}{ Área de borde (parche, clase y paisaje) } \\
\hline & Densidad de borde (clase y paisaje) & Absoluta \\
\hline & & $\begin{array}{l}\text { Ponderada por } \\
\text { contraste }\end{array}$ \\
\hline & Contraste (parche, clase y paisaje) & Absoluto \\
\hline & & Medio \\
\hline & & $\begin{array}{l}\text { Medio ponderado } \\
\text { por tamańos }\end{array}$ \\
\hline \multirow[t]{5}{*}{$\begin{array}{l}\text { Área central (parche, clase } \\
\text { y paisaje) }\end{array}$} & \multicolumn{2}{|l|}{$\begin{array}{l}\text { Área central absoluta (parche, clase } \\
\text { y paisaje) }\end{array}$} \\
\hline & \multicolumn{2}{|l|}{ Área central relativa (clase y paisaje) } \\
\hline & \multicolumn{2}{|l|}{ Área central media (clase y paisaje) } \\
\hline & Variabilidad de área central & Absoluta \\
\hline & (clase y paisaje) & Relativa \\
\hline \multirow{4}{*}{$\begin{array}{l}\text { Distancia con vecinos } \\
\text { (paisaje) }\end{array}$} & \multicolumn{2}{|l|}{ Distancia con vecinos absoluta (parche) } \\
\hline & \multicolumn{2}{|l|}{$\begin{array}{l}\text { Distancia con vecinos media (clase } \\
\text { y paisaje) }\end{array}$} \\
\hline & Variabilidad (clase y paisaje) & Absoluta \\
\hline & & Relativa \\
\hline \multirow[t]{4}{*}{ Diversidad (paisaje) } & \multirow[t]{3}{*}{ Riqueza (paisaje) } & Absoluta \\
\hline & & Relativa \\
\hline & & Densidad \\
\hline & Igualdad (paisaje) & \\
\hline \multirow[t]{2}{*}{$\begin{array}{l}\text { Contagio e interspersión } \\
\text { (clase y paisaje) }\end{array}$} & $\begin{array}{l}\text { Agregación o agrupamiento } \\
\text { (clase y paisaje) }\end{array}$ & \\
\hline & $\begin{array}{l}\text { Entremezcla entre tipos de parches } \\
\text { (clase y paisaje) }\end{array}$ & \\
\hline
\end{tabular}

Fuente: Elaboración propia con base en McGarigal y Marks (1995). 
A continuación se plantean los efectos de la ocurrencia del determinante de orden económico sobre la estructura del paisaje cultural.

\subsection{Aumento de la dominancia de la clase económica}

Este aumento se explica y deriva principal y directamente del principio de exclusión, y de forma menos directa del principio de rentabilidad. La dominancia es el complemento -o sea, el inverso- de la igualdad (dominancia $=1$ - igualdad, o viceversa) (McGarigal y Marks, 1995); por tanto, un aumento de la dominancia de la clase económica implica una disminución de la igualdad entre las diferentes clases o tipos de parches que conforman el paisaje, por ejemplo, la clase ecológica. Es decir, se genera una dominancia y desigualdad crecientes de la clase económica sobre la clase ecológica.

La diversidad de un sistema, que es una relación no lineal entre riqueza (cantidad de tipos de elementos constituyentes del sistema, en este caso cantidad de tipos de parches) y abundancia (cantidad de unidades de cada tipo de elemento constituyente del sistema, en este caso cantidad de parches de cada tipo de parche o clase), indica la capacidad potencial de reacción del sistema. Además, la diversidad máxima para cualquier nivel de riqueza se basa en una distribución igualitaria entre los diferentes tipos de parches (máxima igualdad). Por tanto, el aumento de la dominancia de la clase económica y la disminución de la igualdad que aquello implica, resulta en una menor diversidad del sistema y esto a su vez en un decremento de la capacidad potencial de reacción del sistema (especialmente ecológica), en este caso del paisaje cultural.

Según McGarigal y Marks (1995), la igualdad, la riqueza y la diversidad no expresan ninguna información explícita respecto a qué tipos de parches (clases) pueden ser de mayor significancia ecológica. Sin embargo, para tender hacia la sustentabilidad de la generación de servicios ecológicos es necesario lograr mantener un cierto nivel de diversidad, lo que para el caso del manejo del paisaje cultural implica otorgarle mayor prioridad a los parches y a las clases que presentan menor dominancia en determinas circunstancias particulares.

La teoría biogeográfica de islas predice que la probabilidad de ocupación de un parche por algunas especies y la riqueza de especies son función del tamaño del parche y de su aislamiento (McArthur y Wilson, 1967). Como consecuencia del aumento de la dominancia de la clase económica, el aislamiento de los parches ecológicos tenderá a aumentar. Es importante recalcar que este aumento de la fragmentación de la clase ecológica ocurre con mayor intensidad a una escala espacial mayor que la escala espacial objeto de diseño, manejo y planificación (especialmente si 
dicha unidad de diseño y planificación del paisaje cultural la manejan actores sociales privados); esto ya que, por ejemplo a escala predial (consideremos al predio como la unidad administrativa total manejada por algún actor social en la que se realiza alguna actividad económica-productiva), los escasos relictos de parches correspondientes a la clase ecológica tienden a encontrarse agrupados. Probablemente el aumento de la dominancia de la clase económica derivará en una menor ocupación y recolonización de los parches correspondientes a la clase ecológica, y en una disminución de la riqueza de especies.

\subsection{Disminución de la riqueza de la clase económica}

Esto significa una disminución de la cantidad de subclases económicas, es decir, una reducción de los tipos de parches correspondientes a la clase económica. Esta disminución de la cantidad, así como de la densidad, de las subclases económicas es producto sobre todo de los principios de especialización y de monoproductividad. Además, resultado de la dominancia de la clase económica tendiente a la exclusividad espacial, la disminución de la riqueza de la clase económica determina que la riqueza del paisaje total disminuya en una magnitud similar a la que se reduce la riqueza de la clase económica.

Las consecuencias ecológicas de esto son una pérdida del potencial de coexistencia de especies y una contracción y expansión de ciertas poblaciones, derivando ambas probablemente en una disminución de la riqueza de especies y de la biodiversidad, en especial en el largo plazo. Esto potencia la disminución de la heterogeneidad del paisaje; finalmente ocurre una disminución de la diversidad del paisaje cultural, sobre todo ecológica.

\subsection{Aumento del contagio de la clase económica}

El aumento del contagio de la clase económica deriva y se explica principal y directamente por el principio del contagio, y de forma menos directa por los principios de conectividad y circuitería y de exclusividad. Ese aumento del contagio de la clase económica ocurre con mayor intensidad entre los parches correspondientes a la misma especialización o subclase económica. Como ya se explicó, el contagio es una variable que mide la interpersión o entremezcla de diferentes tipos de parches (diferentes clases) y la dispersión del tipo de parche respectivo; o sea, el contagio se refiere a una combinación entre interspersión y dispersión.

El contagio afecta la interacción entre parches y especialmente entre clases, siendo un adecuado y certero indicador de aquello. El aumento 
del contagio de la clase económica se asocia a una mayor fragmentación de la clase ecológica. Se recalca nuevamente que el aumento de la fragmentación de la clase ecológica producto de la ocurrencia del determinante de orden económico, sucede con mayor intensidad a una escala espacial mayor que la que es objeto de diseño, manejo y planificación, ya que a esa escala los pocos relictos de parches correspondientes a la clase ecológica tienden a encontrarse agrupados por el alto contagio de la clase económica. Esa fragmentación de la clase ecológica genera que los vínculos espaciales entre los parches correspondientes a la clase ecológica y la ocurrencia de bucles o rutas alternativas disminuyan, factores que reducen la eficacia y eficiencia de los movimientos de especies y de los flujos ecológicos en general. Esta fragmentación ecológica del paisaje presenta varias consecuencias ecológicas más puntuales: disminución de la ocurrencia de intersecciones de corredores de vegetación natural, donde la riqueza de especies biológicas es mayor que en el resto del paisaje; disminución de la cantidad de hábitat; cambio en la composición biológica al generar un aumento del hábitat de borde respecto al hábitat de interior; aumento de las probabilidades de extinción local por mayor aislamiento de los parches y menores probabilidades de recolonización, lo que es función de la distancia y de las características ecológicas de la matriz intermedia.

En definitiva, el aumento del contagio de la clase económica, sobre todo y con mayor intensidad en una escala espacial mayor a la del objeto de diseńo, manejo y planificación, quizá genera un empobrecimiento cualitativo y una pérdida cuantitativa de hábitat, un cambio de la composición de las especies biológicas producto del cambio de la abundancia relativa de hábitat de borde en comparación con el hábitat de interior, un aumento de las probabilidades de disminución de la biodiversidad.

\subsection{Disminución de la interspersión y yuxtaposición a nivel de clases y del paisaje cultural}

La disminución de la interpersión en el paisaje cultural producto del determinante de orden económico se debe y explica principal y directamente por el principio del contagio y de la contigüidad, y de forma menos directa por los principios de conectividad y circuitería y de exclusividad. Esa disminución de la interspersión ocurre a nivel del paisaje cultural, a nivel de cada una de las clases que constituyen el paisaje cultural, y especial y más intensamente en la clase económica.

La interspersión evalúa cada parche por sus adyacencias con todos los otros tipos de parches (McGarigal y Marks, 1995). Valores altos de interspersión resultan de paisajes en los cuales los diferentes tipos de parches 
(clases) están muy interspersados (alta equiparidad de las adyacencias entre los diferentes tipos de parches). La interspersión es inversamente proporcional al contagio (McGarigal y Marks, 1995). Por lo anterior, las consecuencias ecológicas de la disminución de la interspersión y yuxtaposición en general tenderán a ser las mismas que las derivadas del aumento del contagio de la clase económica (aumento del fraccionamiento ecológico en un paisaje cultural correspondiente a una escala espacial mayor que la que es objeto de diseño, manejo y planificación; disminución de la eficacia y eficiencia de los flujos ecológicos; aumento de las probabilidades de extinciones locales y una disminución de las probabilidades de recolonización de parches).

\subsection{Aumento del tamaño de clase económica y de sus parches}

Este aumento se explica y deriva directamente del principio de exclusividad. El aumento del tamaño medio de los parches correspondientes a la clase económica se explica y deriva directamente del principio de escala espacial. Como ya se estableció, ante la ocurrencia del determinante de orden económico disminuye el número de parches correspondientes a la clase económica, por lo que el aumento del tamaño de dicha clase (dominancia) se produce mediante un aumento del tamańo medio de sus parches. Este incremento del tamaño medio es un indicador de menor fragmentación de la clase económica y así de mejor funcionalidad económica, consecuentemente con el determinante de orden económico. En general, el aumento del tamaño de la clase económica tenderá a provocar una disminución del tamaño de la clase ecológica, la que puede expresarse mediante un menor número de parches correspondientes a la clase ecológica, un menor tamaño medio de esos parches, o ambos.

El área tiene una gran importancia ecológica de por sí. Hay evidencia considerable de que, por ejemplo, la riqueza de especies de aves y la presencia y abundancia de algunas especies están muy correlacionadas con el tamaño de parche (McGarigal y Marks, 1995). La información acerca del tamaño de parche se puede usar por sí sola para modelar la riqueza de especies, la ocupación de parches y los patrones de distribución de especies en un paisaje. La teoría de biogeografía de islas predice que la probabilidad de ocupación de un parche o la riqueza de especies es función, al menos en parte, del tamaño del parche (MacArthur y Wilson, 1967). Finalmente, la disminución del tamaño de la clase ecológica (por reducción del número de parches de dicha clase, del tamaño medio de estos, o ambas) resultante del aumento del tamaño de la clase económica, quizá provoque una disminución de la riqueza y abundancia de especies y así de la biodiversidad, especialmente en el largo plazo. 


\subsection{Disminución de la densidad de parches de la clase económica}

Esta disminución deriva directamente de los principios de escala espacial y de la mínima cantidad. Tal reducción, junto con lo que plantea el principio de exclusividad respecto a la dominancia de la clase económica tendiendo hacia la exclusividad espacial, y lo que plantea el principio de la especialización, deriva en una disminución de la heterogeneidad del paisaje, sobre todo ecológica.

\subsection{Disminución de la cantidad de parches de clase económica}

La disminución de la cantidad de parches correspondientes a la clase económica se explica y deriva principal y más directamente del principio de la mínima cantidad y de la escala espacial. Aunque de forma menos directa, también están relacionados los principios de la especialización y de la monoproductividad. La cantidad de parches correspondientes a la clase ecológica también tiende a disminuir, ya que la superficie correspondiente a la clase económica tenderá hacia la exclusividad espacial (principios de la rentabilidad, de la exclusión y de la artificialización). En particular disminuye la cantidad de parches correspondientes a la clase ecológica que presentan un tamaño suficiente para sustentar poblaciones vegetales y/o animales. La máxima expresión del determinante de orden económico corresponde a la ausencia total de parches correspondientes a la clase ecológica.

El número de parches de un tipo particular de hábitat puede afectar varios procesos ecológicos: el número de subpoblaciones en una metapoblación para especies asociadas exclusivamente con este tipo de hábitat; la estabilidad de las interacciones entre especies y la coexistencia en los sistemas predador-presa y de competencia (Kareiva, 1985). La disminución del número de parches, ya sea mediante la eliminación de uno o más parches o por medio de la eliminación de uno o más tipos de parches, derivará en la reducción de la cantidad de especies (Dramstad et al., 1996). Entonces, la principal consecuencia ecológica de la eliminación de tipos de parches producto de la especialización y monoproductividad será una disminución del potencial de coexistencia de especies. Las consecuencias ecológicas de la reducción de la cantidad de parches correspondientes a la clase ecológica son las mismas que aquéllas de la disminución de la cantidad de parches correspondientes a la clase económica, pero en una magnitud bastante más grande por la mayor calidad de hábitat y valor ecológico. 


\subsection{Disminución del borde y aumento del área central}

La disminución del largo y densidad del borde, producto del determinante de orden económico, deriva y se explica sobre todo por los principios de escala espacial y de la mínima cantidad, y menos directamente por el principio de exclusión. El área central en términos propios de la ecología del paisaje corresponde al área total menos el área de borde en un parche, por lo que el aumento del área central es una consecuencia directa de la disminución del borde. Esta reducción y el aumento del área central, y más aún interpretados conjuntamente con el aumento de la dominancia de la clase económica, constituyen un sólido indicador de la reducción en la fragmentación de la clase económica, en especial en el paisaje cultural correspondiente a la escala espacial objeto de diseño, manejo y planificación, por ejemplo la escala predial. Lo anterior avala el aumento del contagio de la clase económica y es coherente con aquello. La significancia ecológica de estos cambios de borde y de área central radica en que implica un cambio en la abundancia relativa de hábitat de borde y de hábitat de interior, y en consecuencia en la composición de especies biológicas propias de ambos tipos de hábitat. Es importante hacer notar que el problema ecológico principal del cambio de la abundancia relativa del hábitat de borde y de interior, y el consiguiente cambio de la composición de especies biológicas, es que dichos cambios y la tecnologización necesaria para aquello ocurren a una intensidad y tasa mucho mayor que la que ha experimentado el sistema en su historia evolutiva, y por tanto que a la que el mismo sistema está adaptado.

\subsection{Aumento de contraste entre parches de clase económica y unidades espaciales contiguas}

El aumento del contraste se explica y deriva principalmente de los principios de artificialización e intensificación, ya que es mediante la implementación tecnológica que se genera tal contraste; además deriva de los principios de especialización y monoproductividad. Es importante señalar que ante la ocurrencia del determinante de orden económico, y sobre todo por el principio de exclusión (además de otros como el de la especialización y el de la monoproductividad), el aumento del contraste entre los parches de la clase económica y las unidades espaciales contiguas a ellos implica una tendencia general hacia el aumento del contraste entre las diferentes unidades espaciales del paisaje cultural en su totalidad.

El contraste refleja la magnitud de la diferencia entre parches para uno o más atributos ecológicos a cierta escala espacial (McGarigal y Marks, 1995). La significancia ecológica del contraste radica sobre todo en el 
efecto borde. Por ejemplo, los cambios microclimáticos se extenderían más adentro a lo largo de un borde con contraste mayor (McGarigal y Marks, 1995), y el grado de contraste entre el parche hábitat focal y su entorno influenciaría la dispersión y supervivencia y así afectaría el grado de aislamiento del parche. Bordes de alto contraste pueden inhibir o impedir la búsqueda de recursos suplementarios en el entorno por parte de algunos organismos. Al contrario, algunas especies parecen preferir la yuxtaposición de tipos de parches con alto contraste (Dunning et al., 1992). El aumento del contraste producto del determinante de orden económico provoca un aumento del hábitat de borde, por la mayor penetración de las condiciones propias de borde hacia el interior del parche. Esto, en principio, generaría una alteración en la composición biológica, provocando un aumento de la abundancia relativa de las especies que están más adaptadas a las condiciones del hábitat de borde respecto a aquéllas que están más adaptadas a las condiciones del hábitat de interior. Además, este aumento del contraste puede provocar contracciones o expansiones poblacionales, así como una disminución o un aumento en la riqueza de especies. Es importante recalcar que por la presencia de una matriz constituida principalmente por la clase económica que presenta una gran pobreza biológica (sobre todo por los principios de especialización y monoproductividad además de los principios de artificialización e intensificación), el aumento del contraste entre unidades espaciales en este caso es ecológicamente más significativo que lo que ocurra con el hábitat y las especies de borde o de interior. Lo que suceda con el efecto borde adquiere menor importancia ecológica que el aumento del contraste entre las unidades espaciales producido por la simplificación de los ecosistemas correspondientes a la clase económica dominante mediante la artificialización tecnológica.

\subsection{Disminución de la complejidad de las formas de los parches de clase económica}

La disminución de la complejidad de las formas de los parches correspondientes a la clase económica deriva directamente del principio de la geometrización. Tal reducción, junto con los principios de exclusión y de rentabilidad, implica que el paisaje cultural total muestre y exprese una geometrización general de sus unidades espaciales.

La significancia ecológica primaria de la forma de los parches en el paisaje se relaciona con el efecto borde. Esta simplificación y geometrización de las unidades espaciales en principio provocaría un aumento de la abundancia relativa del hábitat de borde. La consecuencia ecológica principal de esto es que ese cambio composicional ocurre a una intensidad y 
tasa mayores que la que ha experimentado el sistema en su historia evolutiva y, en consecuencia, a la que el mismo sistema esta ecológicamente adaptado. Además, la geometrización de las formas de las unidades espaciales provoca una disminución de las interacciones entre las unidades espaciales contiguas, y así deteriora la funcionalidad ecológica del sistema.

\subsection{Disminución de la distancia entre parches de la clase económica}

Esta disminución entre los parches correspondientes a la clase económica es producto sobre todo del principio de la contigüidad, y más indirectamente del principio de contagio, de conectividad y circuitería y de exclusión. Esto ocurre con más fuerza entre los parches correspondientes a una misma especialización o subclase económica.

Como se ha mostrado, la distancia entre los vecinos (parches de un mismo tipo) más cercanos puede influenciar procesos ecológicos. Hace algunos años hubo una proliferación de modelos matemáticos sobre dinámicas poblacionales e interacción de especies en poblaciones subdivididas espacialmente (Kareiva, 1985), y según los resultados las dinámicas poblacionales locales de plantas y animales en un parche son influenciadas por sus proximidades a otras subpoblaciones de la misma especie o especies competidoras (McGarigal y Marks, 1995). Opdam y Schotman (1987) revisaron estudios que demostraban empíricamente un efecto del aislamiento sobre comunidades de aves en varios parches hábitat. La distancia entre parches juega un rol crítico en la teoría biogeográfica de islas (McArthur $y$ Wilson, 1967) y en la teoría de metapoblaciones (Levins, 1970), y se ha discutido en el contexto de la conservación biológica (por ejemplo, Burkey, 1989). Interpretando conjuntamente la variabilidad de la distancia entre vecinos más cercanos con la distancia media entre estos, se puede concluir respecto a la regularidad y concentración del patrón de distribución espacial de parches de un mismo tipo. Las consecuencias ecológicas generales de la disminución de la distancia entre parches correspondientes a la clase económica, y la consiguiente tendencia hacia el aumento de la contigüidad entre tales parches, corresponden a cierta tendencia a un mayor fraccionamiento de la clase ecológica en una escala espacial mayor que aquélla objeto de diseño, manejo y planificación. Esto deriva en una disminución de la eficacia y eficiencia de los flujos ecológicos y un aumento de las probabilidades de disminución de la biodiversidad.

Con base en las significancias ecológicas mencionadas, a continuación se plantean las principales consecuencias ecológicas de los efectos estructurales de la ocurrencia del determinante de orden económico. Se recalca 
nuevamente que tales consecuencias ocurren y se manifiestan especialmente en el largo plazo. Estas consecuencias ecológicas son:

- Aumento de la fragmentación ecológica del paisaje cultural. Es importante recalcar una vez más que el aumento de la fragmentación de la clase ecológica ocurre sobre todo en una escala espacial mayor que la que es objeto de diseńo, manejo y planificación; por ejemplo, mayor que la escala predial. Esto presenta consecuencias ecológicas de mayor alcance e intensidad que si ocurriese a escala predial, ya que al suceder a una escala espacial mayor la distancia entre los parches correspondientes a la clase ecológica también es mayor. Las consecuencias ecológicas de esto son complementarias y sinérgicas con el gran deterioro de la matriz (constituida principalmente por la clase económica) producto de la simplificación ecosistémica y degradación del hábitat.

- Disminución de la eficacia y de la eficiencia de los flujos ecológicos.

- Reducción de la ocupación y recolonización de parches hábitat por las especies biológicas.

- Deterioro o degradación cualitativa y disminución o pérdida cuantitativa del hábitat.

- Disminución del potencial de coexistencia de especies y contracción y expansión de ciertas poblaciones biológicas.

- Aumento de las probabilidades de extinciones locales.

- Menor riqueza y abundancia de especies y así disminución de la biodiversidad.

- Incremento de disfuncionalidades del paisaje cultural, especialmente ecológicas.

La figura IV muestra esquemáticamente las consecuencias ecológicas del efecto del determinante de orden económico sobre la configuración del paisaje cultural, o sea, sobre el componente de su estructura espacialmente explícito.

La figura IV plantea y muestra que un aumento de la fragmentación ecológica del paisaje provoca, o al menos aumenta, las probabilidades de que ocurra una disminución de la interacción entre las unidades espaciales que constituyen la clase ecológica. Esto provoca, o al menos aumenta, las probabilidades de una disminución de la eficacia y eficiencia de los flujos ecológicos (de especies animales y vegetales, energía, nutrientes, etc.), lo cual a su vez en principio genera un deterioro y una pérdida cuantitativa del hábitat, y así una disminución de la abundancia y la riqueza de especies (tamaños poblacionales y cantidad de especies, respectivamente) y en consecuencia una disminución de la biodiversidad. 


\section{Figura IV}

Esquema de las principales consecuencias ecológicas derivadas del efecto del determinante de orden económico sobre la configuración del paisaje cultural

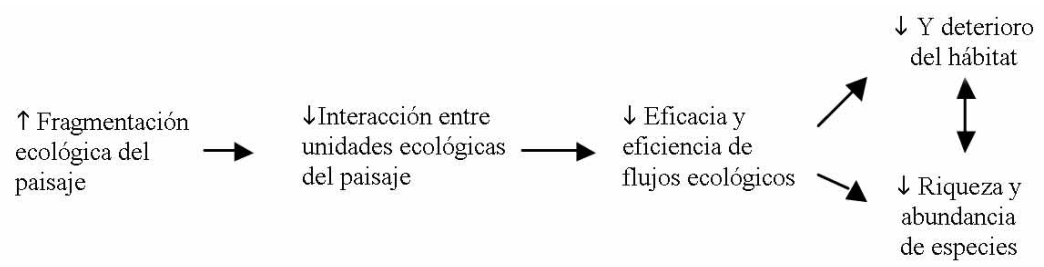

Fuente: Elaboración propia.

La figura $\mathrm{v}$ muestra esquemáticamente las principales consecuencias ecológicas del efecto del determinante de orden económico sobre la composición del paisaje cultural, es decir, sobre el componente espacialmente no explícito de su estructura. Para fines ilustrativos se mostraron primero en diferentes figuras las consecuencias del determinante de orden económico sobre la configuración y composición del paisaje cultural, aunque en realidad éstas ocurren interrelacionadas e interactuantes y de esa manera serán consideradas más adelante.

Como se muestra en la figura v, la imperancia del determinante de orden económico produce una simplificación del paisaje y especialmente de su dimensión y clase ecológica, disminuyendo la riqueza e igualdad del paisaje, lo que deriva en una reducción de la diversidad del sistema. Esto conlleva a una menor capacidad de reacción del sistema, y así una disminución del potencial de resiliencia y de restauración ecológica, lo que se relaciona con el aumento de las probabilidades de ocurrencia de disfuncionalidades ecológicas en el paisaje, y a su vez con los efectos del determinante de orden económico sobre la configuración del paisaje.

La figura vi muestra las principales consecuencias de la ocurrencia del determinante de orden económico sobre la funcionalidad ecológica del paisaje. Se hace notar nuevamente que para fines ilustrativos se han mostrado primero en diferentes figuras las consecuencias del determinante de orden económico sobre la configuración, composición y funcionalidad ecológica del paisaje cultural, aunque en realidad éstas ocurren interrelacionadas e interactuantes y de esa manera serán consideradas más adelante.

La figura vi muestra que un aumento de la tasa de tecnologización (implementación tecnológica) provoca un desacoplamiento entre el mecanismo de autorregeneración organizada, propio de los sistemas vivos, que corresponde a la autopoiesis, y el proceso adaptativo, el cual al estar 


\section{Figura $\mathrm{V}$}

Esquema de las principales consecuencias ecológicas derivadas del efecto del determinante de orden económico sobre la composición del paisaje cultural

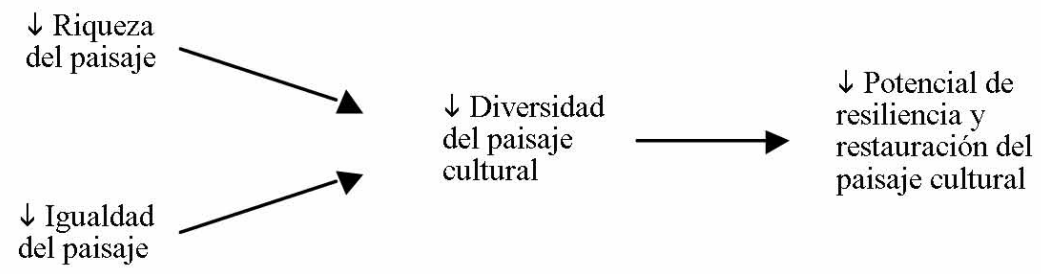

Fuente: Elaboración propia.

\section{Figura VI}

Esquema de las principales consecuencias ecológicas del efecto del determinante de orden económico sobre la funcionalidad del paisaje cultural

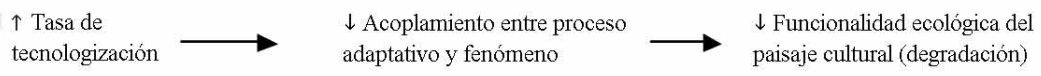

Fuente: Elaboración propia.

determinado y condicionado por una considerable tecnologización funciona con una dinámica y plazos muy diferentes que los procesos, flujos y mecanismos biológicos y ecológicos. Así, se reemplazan los operadores biológicos por las máquinas tecnológicas, pasando la red funcional del sistema a estar cada vez más constituida por estas últimas. Ese desacoplamiento entre adaptación y autopoiesis implica un deterioro de la funcionalidad ecológica del paisaje.

Finalmente, el deterioro de los flujos ecológicos asociado a la disminución de la conectividad ecológica, la disminución del potencial de resiliencia y de restauración ecológicas asociada a la disminución de la diversidad ecológica, ambos consecuencia del efecto del determinante de orden económico sobre la configuración y composición del paisaje cultural, respectivamente, junto con la degradación de su funcionalidad ecológica, resulta en una disminución de la adaptabilidad ecológica (capacidad adaptativa). Es decir, se plantea un aumento de las probabilidades de deterioro de los servicios ecológicos y una reducción de la magnitud de generación de tales servicios; esto es, un aumento de las probabilidades de insustentabilidad de la generación de servicios ecológicos o ecosistémicos (figura vII). 


\section{Figura VII}

\section{Esquema de las principales consecuencias ecológicas del determinante de orden económico sobre el paisaje cultural}

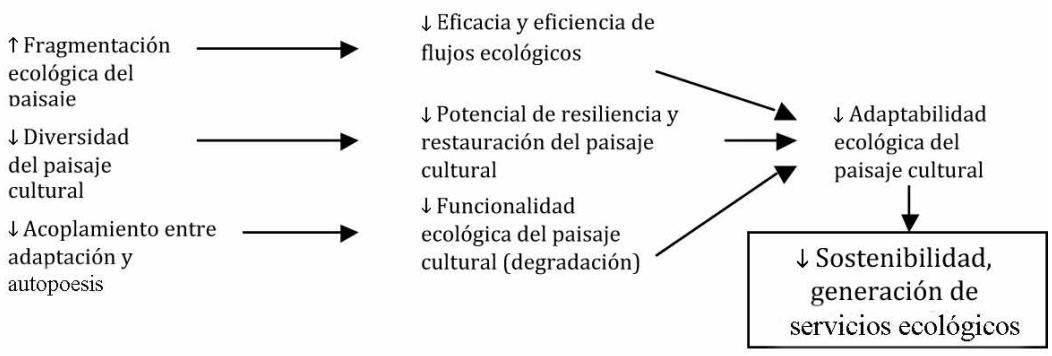

Fuente: Elaboración propia.

Lo anterior se puede incorporar en las relaciones jerárquicas de los principios propios del determinante de orden económico. Las partes o ejes derecho e izquierdo de la figura iII se relacionan más directamente con las figuras IV y $\mathrm{v}$ y con la figura VI, respectivamente.

La especialización del paisaje cultural es un mecanismo que, mediante la simplificación, conduce a un aumento de la adaptación inmediata y así hacia un aumento de la eficiencia. Esa simplificación en el paisaje conlleva una disminución de su diversidad y un aumento de la segregación territorial asociada a la fragmentación ecológica. Así, los principios de la eficiencia y de la especialización, que representan la base fundamental (nivel axiomático y nivel técnico) del eje derecho de la figura III, están más directamente relacionados con las figuras iv y v. Por otro lado, la implementación tecnológica es un mecanismo que conduce a un aumento de la tasa de utilización de los recursos. Esa alta tecnologización deriva en un desacoplamiento entre autopoiesis y adaptación, lo que, como se mencionó, conlleva un deterioro de la funcionalidad ecológica del paisaje cultural. Así, los principios utilitario y tecnologista, que representan la base fundamental (nivel axiomático y técnico) del eje izquierdo de la figura III, están más directamente relacionados con la figura vi. El vínculo asociativo entre los ejes derecho e izquierdo de la figura III y entre las figuras IV, v y VI, radica en el principio de la rentabilidad. Esto significa que si el paisaje cultural se diseña en función de la máxima rentabilidad y lucro económico-monetario, se genera un deterioro de su adaptabilidad ecológica y, finalmente, una insustentabilidad de la generación de servicios ecológicos en el largo plazo. 


\section{Conclusiones y reflexiones finales}

El aumento del impacto antrópico sobre los ecosistemas y el deterioro de estos, están asociados a un creciente determinismo del contexto cultural y de la racionalidad imperante en el funcionamiento y la evolución ecológica del paisaje cultural, lo que a su vez indica una mayor importancia por investigar acerca de los estímulos y priorizaciones culturales.

Con base en teorías, modelos y conceptos surgidos desde distintos campos de la ciencia, y considerando datos e información empírica generada de manera observacional y también experimental en estudios disponibles en la literatura científica, se desarrollaron principios, definiciones y planteamientos relacionados entre sí y centrados en conceptos innovadores como el paisaje cultural y el determinante de orden económico. La imperancia de la racionalidad económica deriva en la imperancia del determinante de orden económico, y esto en la dominancia de paisajes culturales funcionales para maximizar el lucro económico valorable monetariamente pero disfuncionales para la sustentabilidad ecológica. Las características estructurales de los paisajes resultantes del determinante de orden económico de mayor significancia ecológica se describieron mediante un sistema de 16 principios organizados jerárquicamente. Se precisaron las consecuencias ecológicas del efecto del determinante de orden económico sobre la configuración y la composición estructural del paisaje y sobre su funcionalidad ecológica. La coexistencia conflictiva entre diferentes determinantes de orden (ecológico, económico y social) en el paisaje cultural, implica una transacción entre la generación de diferentes tipos de servicios, como ecológicos (ecosistémicos), sociales y económicos. Finalmente, la ocurrencia del determinante de orden económico provoca una disminución de la adaptabilidad ecológica del paisaje cultural, lo que disminuye las probabilidades de sustentabilidad de la generación de servicios ecológicos.

La derivación del concepto de sistema en una aproximación en sí misma, ha sido fundamental para el surgimiento de la transdisciplinariedad y de las llamadas ciencias de la complejidad, cuestiones epistemológicamente clave para generar planteamientos operativos respecto a la problemática de la sustentabilidad, para lo cual la integración y la contextualización son atributos fundamentales. Así, el reduccionismo que impera en la ciencia se ha mostrado no operativo ante dicha problemática. El paisaje cultural, al corresponder al resultante de la coevolución sociocultural y ecológica-territorial, integra inherentemente variables de ambos tipos, lo que lo constituye en un objeto de estudio en esencia transdisciplinario y propicio para el entendimiento y manejo del fenómeno de la sustentabilidad. 
Así como la degradación ecológica-territorial actual se ha producido por la acción humana, el mantener y/o recuperar los servicios ecológicos requerirá de un manejo activo, diseño y planificación. Para una mayor diversidad y adaptabilidad ecológica en el paisaje cultural, es necesaria más riqueza de hábitat para una mayor coexistencia de especies; para esto, es fundamental el uso múltiple del territorio, incorporando objetivos y prioridades diversas en el diseño, manejo y planificación del paisaje cultural. La imperancia excluyente de la racionalidad económica y del determinante de orden económico es contraria a la adaptación mutua e integral entre actores sociales, fundamental para un paisaje cultural sustentable. Sólo un cambio en la relación entre los actores sociales y su entorno, en el estilo de artificialización de la naturaleza y del manejo de los recursos naturales, permitirá tender hacia la sustentabilidad.

\section{Bibliografía}

Barr, Neil (2000), Structural change in Australian Agriculture: implications for natural resource management, Department of Natural Resources and Environment, Victoria.

Barr, Neil (2002), "Social trajectories for rural landscaping", Connections, 2, Department of Agriculture and Food Systems, University of Melbourne, Melbourne, pp. 37-45.

Bertalanffy, Ludwig von (1968), General System Theory: Foundations, Development, Applications, George Braziller, Nueva York.

Bertalanffy, Ludwig von (1975), Perspectives of general system theory, Springer Verlag, Nueva York.

Björklund, Johanna, Karin Limburg y Torbjörn Rydberg (1999), “Impact of production intensity on the ability of the agricultural landscape to generate ecosystem services: an example from Sweden", Ecological Economics, 29, International Society for Ecological Economics, Maryland, pp. 269-291.

Burkey, Tormod (1989), "Extinction in nature reserves: the effects of fragmentation and the importance of migration between reserve fragments", Oikos, Journal by the Nordic Ecological Society, 55, Nordic Ecological Society, Lund, pp. 75-81. 
Calabuig, Estanislao de Luis (2002), "Prólogo de la edición española”, en Françoise Burel y Jacques Baudry, Ecología del paisaje: conceptos, métodos y aplicaciones, Mundi-Prensa, París, pp. XV-XVI.

Costanza, Robert, Ralph d'Arge, Rudolf de Groot, Stephen Farber, Monica Grasso, Bruce Hannon, Karin Limburg, Shahid Naeem, Robert V. O'Neill, Jose Paruelo, Robert Raskin, Paul Sutton y Marjan van den Belt (1997), "The value of the world's ecosystem services and natural capital”, Nature, 387, Nature Publishing Group, Londres, pp. 253-260.

Dramstad, Wenche, James Olson y Richard Forman (1996), Landscape Ecology Principles in Landscape Architecture and Land-use Planning, Harvard University Graduate School of Design-Island PressAmerican Society of Landscape Architects, Washington.

Dunning, John, Brent Danielson y Ronald Pulliam (1992), "Ecological processes that affect populations in complex landscapes", Oikos, Journal by the Nordic Ecological Society, 65, Nordic Ecological Society, Lund, pp. 169-175.

Erlwein, Alfredo, Antonio Lara y Alfredo Pradenas (2008), "Industria de celulosa en Chile: un modelo de desarrollo no sustentable", en Adrián Monjeau, Aníbal Parera y Enrique Lacour (coords.), Ecofilosofía, Universidad Atlántida, Buenos Aires, pp. 141-179.

Forman, Richard (2002), "Prefacio", en Françoise Burel y Jacques Baudry, Ecología del paisaje: conceptos, métodos y aplicaciones, MundiPrensa, París, pp. XI-XIII.

Fu, Bo-Jie, Chen-Xia Hu, Li-Ding Chen, Olivier Honnay y Hubert Gulink (2006), "Evaluating change in agricultural landscape pattern between 1980 and 2000 in the Loess hilly region of Ansai County, China", Agriculture, Ecosystems and Environment, 114, Elsevier, Amsterdam, pp. 387-396.

Gell-Mann, Murray (1995), El quark y el jaguar. Aventuras en lo simple y lo complejo, Tusquets, Barcelona.

González-Bernáldez, Fernando (1981), Ecología y paisaje, Blume, Barcelona. 
Hietala-Koivu, Reija (2002), "Landscape and modernizing agriculture: a case study of three areas in finland in 1954-1998", Agriculture, Ecosystems and Environment, 91, Elsevier, Amsterdam, pp. 273-281.

Kareiva, Peter (1985), "Finding and losing host plants by Phyllotreta: patch size and surrounding habitats", Ecology, 66, Ecological Society of America, Nueva York, pp. 1809-1816.

Kuhn, Thomas (1970), La estructura de las revoluciones cientificas, Fondo de Cultura Económica, México.

Lefeuvre, Jean (2002), "De los paisajes del pasado a los paisajes humanizados actuales", en Françoise Burel y Jacques Baudry, Ecología del paisaje: conceptos, métodos y aplicaciones, Mundi-Prensa, París, pp. XII-XXX.

Leff, Enrique (2002), Saber ambiental. Sustentabilidad, racionalidad, complejidad y poder, Siglo XXI, México.

Levins, Richard (1970), "Extinctions”, en Murray Gerstenhaber (coord.), Some Mathematical Questions in Biology: Lectures on Mathematics in the Life Sciences, American Mathematics Society, Providence, Rhode Island, pp. 77-107.

Lockwood, Michael, Sandra Walpole y Carla Miles (2000), Economics of remnant native vegetation conservation on private property, Johnstone Centre, Charles Sturt University, Dubbo, Australia.

MacArthur, Robert y Edward Wilson (1967), The theory of island biogeography, Princeton University Press, New Jersey.

MacLeod, Neil y James Noble (1990), "An economic evaluation of the impact of prescribed fire on pastoral leases in the eucalyptus shrublands of southwestern New South Wales", Environment International, 17, Elsevier, Amsterdam, pp. 151-162.

MacLeod, Neil y John McIvor (2006), "Reconciling economic and ecological conflicts for sustained management of grazing lands", Ecological Economics, 56, International Society for Ecological Economics, Maryland, pp. 386-401. 
Margalef, Ramón (1998), "El marco ecológico para iluminar la sociedad actual”, en Juan Naredo y Fernando Parra (coords.), Economía, ecología y sostenibilidad en la sociedad actual, Siglo XXI, Madrid, pp. 51-66.

Maturana, Humberto (1994), "Chile necesita desindustrializarse", en Marcelo Mendoza (coord.), Todos queríamos ser verdes: Chile en la crisis ambiental, Planeta, Santiago, pp. 19-51.

Maturana, Humberto y Francisco Varela (1972), De máquinas y seres vivos. Una teoría de la organización biológica, Editorial Universitaria, Santiago.

Max-Neef, Manfred (1994), "Por qué un Cristo de plástico acerca más a la gente a la divinidad que un árbol", en Marcelo Mendoza (coord.), Todos queriamos ser verdes. Chile en la crisis ambiental, Planeta, Santiago, pp. 188-216.

McGarigal, Kevin y Barbara Marks (1995), Fragstats: spatial pattern analysis program for quantifying landscape structure, United States (USDA), Portland, Oregon, USA.

Miller, James (1975), "The nature of living systems", Behavioral Sciences, 20, John Wiley \& Sons, New Jersey, pp. 343-365.

Naredo, Juan (1987), “¿Qué pueden hacer los economistas para ocuparse de los recursos naturales? Desde el sistema económico hacia la economía de los sistemas", Pensamiento Iberoamericano, 12, Agencia Española de Cooperación Internacional para el Desarrollo, Madrid, pp. 61-74.

Naredo, Juan (2004), "Diagnóstico sobre la sostenibilidad: la especie humana como patología terrestre", en Actas Jornadas sobre La Sostenibilidad en el Proyecto Arquitectónico y Urbanístico, Escuela Técnica Superior de Arquitectura, Madrid, pp. 1-9.

Naredo, Juan y Fernando Parra (1993), Hacia una ciencia de los recursos naturales, Siglo XXI, Madrid.

Naveh, Zev (2000), "What is holistic landscape ecology? A conceptual introducción", Landscape and Urban Planning, 50, Elsevier, Amsterdam, pp. 7-26. 
Naveh, Zev y Arthur Lieberman (1994), Landscape Ecology. Theory and Applications, Springer, Nueva York.

O’Neill, Robert, Donald Deangelis, Jack Waide y Timothy Allen (1986), A Hierarchical Concept of Ecosystems, Princeton University Press, New Jersey.

Opdam, Paul y Alex Schotman (1987), "Small woods in rural landscapes as habitat islands for woodland birds", Acta Oecológica Generalis, 8, Gauthiers-Villars, París, pp. 269-274.

Pannell, David (1999), Explaining Non-Adoption of practices to prevent salinity in Western Australia: Implications for Policy, University of Western Australia, Crawley, Western Australia.

Primack, Richard, Ricardo Rozzi, Peter Feinsinger, Rodolfo Dirzo y Francisca Massardo (2001), Fundamentos de conservación biológica: perspectivas latinoamericanas, Fondo de Cultura Económica, México.

Röling, Niels (2000), Gateway to the global Garden: Beta/Gamma Science for Dealing with Ecological Rationality, University of Guelph, Ontario.

Ruuska, Riitta, y Juha Helenius (1996), "GIS analysis of change in an agricultural landscape in Central Finland", Agricuture and Food Science in Finland, 5, Scientific Agricultural Society of FinlandMTT Agrifood Research Finland, Helsinki, pp. 567-576.

Santelmann, Mary, Kathryn Freemark, Jean Sifneos y Denis White (2006), "Assessing effects of alternative agricultural practices on wildlife habitat in Iowa, USA", Agriculture, Ecosystems and Environment, 113, Elsevier, Amsterdam, pp. 243-253.

Scheffran, Jürgen (2000), "The dynamic interaction between economy and ecology cooperation, stability and sustainability for a dynamic-game model of resource conflicts", Mathematics and computers in simulation, 53, International Association for Mathematics and Computers in Simulation, Amsterdam, pp. 371-380. 
Simon, Herbert (1962), "The architecture of complexity", Proceedings of the American Philosophical Society, 106, American Philosophical Society, Filadelfia, pp. 467-482.

Subercaseaux-Ugarte, Diego (2007), "Paisaje cultural: implicancias ecológicas de la priorización del lucro económico. Bases teóricoconceptuales y planificación del paisaje cultural", tesis de magister en Recursos Naturales, Pontificia Universidad Católica de Chile, Santiago de Chile.

Varela, Francisco (1993), Linscription corporelle de l'esprit: sciences cognitives et expérience humaine, Seuil, París.

Verlinde, Vim (2002), "Caracterización predial. El caso del Fundo Pahuilmo”, en Juan Gastó, Patricio Rodrigo e Ivonne Aránguiz (coords.), Ordenación territorial, desarrollo de predios y comunas rurales, Pontificia Universidad Católica de Chile-Lom Ediciones, Santiago, pp. 407- 432 .

Vitousek, Peter, Harold Mooney, Jane Lubchenco y Jerry Melillo (1997), "Human domination on Earth's systems", Science, 277, American Association for the Advancement of Science, Washington, pp. 494-499.

Wu, Jianguo y John David (2002), "A spatially explicit hierarchical approach to modeling complex ecological systems: theory and applications", Ecological Modelling, 153, Elsevier, Amsterdam, pp. 7-26.

Recibido: 15 de julio de 2010. Reenviado: 19 de febrero de 2011. Reenviado: 17 de agosto de 2011. Aceptado: 13 de septiembre de 2011.

Diego Subercaseaux-Ugarte. Desde el año 2008 es magíster en recursos naturales por la Pontificia Universidad Católica de Chile; asimismo realizó sus estudios de ingeniero agrónomo en la misma universidad. Actualmente es profesor del Departamento de Gestión Agraria de la Universidad de Santiago de Chile; además es consultor independiente en las áreas ambiental, territorial y ecológica. Ha trabajado en estudios de monitoreo ambiental y de gestión ambiental, difusión de la agroecología y captación 
de opinión pública al respecto, entre otros. Ha colaborado en cursos universitarios y/o académicos en otras instituciones en Chile. Sus líneas de investigación están orientadas a los recursos naturales, la ordenación y planificación territorial, el paisaje cultural, la ecología del paisaje y la agroecología. Es miembro de la Sociedad Científica Latinoamericana de Agroecología (Socla) y secretario del capítulo chileno (Socla-Chile). Actualmente trabaja en la elaboración y publicación de varios artículos académicos y capítulos de libros orientados a temáticas territoriales y del paisaje cultural en el contexto de la sustentabilidad. Recientemente publicó el artículo "Dimensión ecológica del paisaje cultural en el siglo xxı", Revista de la Escuela de Arquitectura de la Universidad de Talca, 4, Talca, pp. 60-73 (2010). 